Non-peer reviewed preprint submitted to EarthArXiv

\title{
A HeURistic APPROACH FOR MODELING THE SURFACE HISTORIES OF CRATONS USING APATITE FISSION-TRACK "SUPER SAMPLES"
}

\author{
Kalin T. McDannell (Dartmouth College) \\ Paul B. O'Sullivan (GeoSep Services) \\ Kerry Gallagher (Université de Rennes 1) \\ Scott Boroughs (Washington State University)
}

manuscript submitted to Earth $\mathcal{E}$ Planetary Science Letters

\footnotetext{
citation: McDannell, K.T., O'Sullivan, P.B., Gallagher, K., Boroughs, S., 2022. A heuristic approach for modeling the surface histories of cratons using apatite fission-track "super samples". EarthArXiv, https://doi.org/10.31223/X5M05W.
} 


\title{
A heuristic approach for modeling the surface histories of cratons using apatite fission-track "super samples"
}

\author{
Kalin T. McDannell* \\ Department of Earth Sciences, Dartmouth College, Hanover NH 03755, United States \\ Paul B. O'Sullivan \\ GeoSep Services, 1521 Pine Cone Road, Moscow ID 83843, United States \\ Kerry Gallagher \\ Géosciences Rennes, Université de Rennes 1, Rennes 35042, France \\ Scott Boroughs \\ School of the Environment, Washington State University, Pullman WA 99164, United States
}

\begin{abstract}
Understanding the long-term erosion and burial history of cratons is often challenging due to the incompleteness of the geologic record. Low-temperature thermochronology has been used to provide constraints on these histories and apatite fission-track dating has long been one of the preferred methods. In terms of analytical protocol the convention has been to measure $\sim 100$ confined track lengths and to produce $\sim 20$ single-grain ages. These data are then inverted for thermal history along with sparse constraints and other assumptions pertaining to the regional geologic evolution. However, imposing constraints will influence the form of the inferred thermal histories. In some cases this step may limit impartial assessment of the unknown history in terms of what features are required by the data and those that the data are consistent with (or at least do not contradict). Here we present a study involving apatite fission-track data collected from central Canadian Shield basement rocks with more dated age grains and $\sim 3-7 \times$ the number of track-length measurements when compared to a conventional analysis. We refer to these data as "super samples" (AFTSS) and show such data can improve resolution of complex histories involving episodic reheating and partial annealing. Importantly for the data we discuss, AFTSS can also be used to independently infer past geologic conditions without the enforcement of many a priori constraints during modeling - such as the approximate times of past basement exposure. Modeling in this way is guided by a heuristic philosophy regarding the use of thermal history constraints. This allows us to examine the ability of the model to independently infer geologically plausible time-temperature paths from the fission-track data alone. Inversions of these data establish that
\end{abstract}

\footnotetext{
*Corresponding author: kalin.t.mcdannell@dartmouth.edu
} 
the currently exposed basement near the Hudson Bay Basin was buried in the middle Paleozoic and late Mesozoic, in agreement with the preserved regional rock record and adding further evidence to suggest that the basin is an erosional remnant. The AFTSS data alone imply two reheating events and indirectly require periods at cooler (near-surface) conditions in the latest Neoproterozoic to early Paleozoic and in the Jurassic to early Cretaceous - the timing of which are consistent with known Hudson Platform unconformities. We recommend that cratonic basement rocks that may have experienced episodic burial reheating $(\sim 60$ to $<$ $100^{\circ} \mathrm{C}$ ) and partial annealing over hundreds of millions of years should have a minimum of 250-300 track lengths collected to provide adequate time-temperature information for thermal history modeling.

Keywords: apatite fission track, cratons, thermochronology, Bayesian modeling, Canadian Shield, burial history

\section{Introduction}

3

4

Cratons or shields are the ancient nuclei of continents that are considered to have been tectonically stable since the Archean-Paleoproterozoic. These regions are typically characterized by low topographic relief and Precambrian igneous and metamorphic basement exposed at the surface. Many shields are devoid of sedimentary cover - making reconstruction of their post-orogenic geological history difficult. For example, most of the Canadian interior is comprised of Precambrian basement sporadically covered only by thin early Paleozoic or middle-late Mesozoic sedimentary strata (e.g., Sloss, 1963; Telford and Long, 1986; Norris, 1993; Pinet et al., 2013; Burgess, 2019) — leaving much of the Phanerozoic geological history an open question. To address the potential to recover this missing record, apatite fission-track (AFT) thermochronology has been one of the primary tools used to constrain the potentially complex burial and erosion histories of cratons (Kohn and Gleadow, 2019, for review).

The AFT thermochronometer provides time and temperature information from the damage features or 'tracks' produced by the energetic fission of ${ }^{238} \mathrm{U}$ within the apatite crystal lattice (e.g., Fleischer and Price, 1963). The number of spontaneous tracks per unit area is related to the amount of $U$ in the grain and thus can provide an estimate of the time (i.e., apparent age) over which tracks have accumulated and been preserved in the crystal. Fission tracks form continuously over time with an initial etched length of $\sim 16-17 \mu \mathrm{m}$, and fade or anneal when subjected to higher temperature, resulting in a nearly equivalent reduction in track density (per area) across the etched grain surface (e.g., Gleadow and Duddy, 1981). Observations of borehole samples showed that with increasing depth, mean track length is reduced with increasing temperature (Gleadow et al., 1986; Fig. 1). As a consequence, annealing decreases the 'age' of the sample as each track is shortened to a degree reflecting the maximum temperature experienced during its history before being totally annealed at 
approximately $110-120^{\circ} \mathrm{C}$ (Gleadow and Duddy, 1981; Green et al., 1986; Gleadow et al., 1986). Laboratory experiments have also demonstrated that resistance to thermal annealing is influenced by apatite composition, primarily $\mathrm{Cl}$ and various elemental substitutions such as $\mathrm{Fe}, \mathrm{OH}, \mathrm{Mg}, \mathrm{Na}, \mathrm{Mn}$, and $\mathrm{Sr}$ that enhance track retentivity compared to common fluorapatite (Green et al., 1985; Carlson et al., 1999; Barbarand et al., 2003). Apatite composition is measured directly by electron microprobe or laser ablation inductively coupled plasma mass spectrometry (LA-ICPMS) - although it is commonly estimated indirectly by proxy with the $\mathrm{D}_{\text {par }}$ parameter (track etch-pit diameter; e.g., Donelick et al., 2005). Grain chemistry provides a means for approximating the track annealing kinetics, which are a critical requirement for thermal history modeling. (e.g., Laslett et al., 1987; Ketcham et al., 1999; Donelick et al., 2005; Ketcham, 2019).

The temperature range of the AFT partial annealing zone $\left(\mathrm{PAZ} ; \sim 120-60^{\circ} \mathrm{C}\right)$ varies as a function of the annealing kinetics and the rock cooling rate (Gleadow and Duddy, 1981; Green et al., 1986; Gleadow et al., 1986; Duddy et al., 1988). The length of a given fission track will reflect to a large degree the maximum temperature that track experienced, whereas the distribution of track lengths provides key information on the structure of the thermal history. The ages can inform us about the overall duration of, and sometimes timing of events in, the overall thermal history. Figure 1 conceptually demonstrates this using a forward model for a hypothetical host rock that experienced four different simplified thermal histories, including: (1) rapid cooling followed by quiescence; (2) linear, slow cooling at a typical 'cratonic rate' of $\sim 0.2^{\circ} \mathrm{C} / \mathrm{My}$; (3) slow cooling to the surface, followed by reheating to $65^{\circ} \mathrm{C}$ and cooling out of the PAZ; and (4) same style as history 3 except reheating to $85^{\circ} \mathrm{C}$ within the PAZ. Each of these histories produce characteristic track length distributions (Fig. 1B-E) that are diagnostic of the type of history the AFT sample experienced. The histories in Figure 1A yield either, a unimodal (normal) distribution of long track lengths of $\sim 15 \mu \mathrm{m}$ for the rapid cooling scenario; a unimodal negative skew distribution for slow cooling with a mean length of $\sim 14 \mu \mathrm{m}$; a unimodal broad or flattened distribution with a similar mean length as the slow cooling case; and a bimodal distribution for the $85^{\circ} \mathrm{C}$ reheating example. The progression from Figure $1 \mathrm{~B}-\mathrm{E}$ generally shows that track length distributions become broader and shorter with increased magnitude and duration of heating (e.g., Gleadow et al., 1986). From these simple models, we can see that track lengths are essential for understanding thermal history.

\section{Motivation}

For cratonic studies, many rock samples are often collected across a broad area and these samples then undergo standard mineral separation and AFT analysis. The AFT data are then modelled within a framework of geologic constraints (or geologic assumptions/interpretations) for the given study area. However, when 

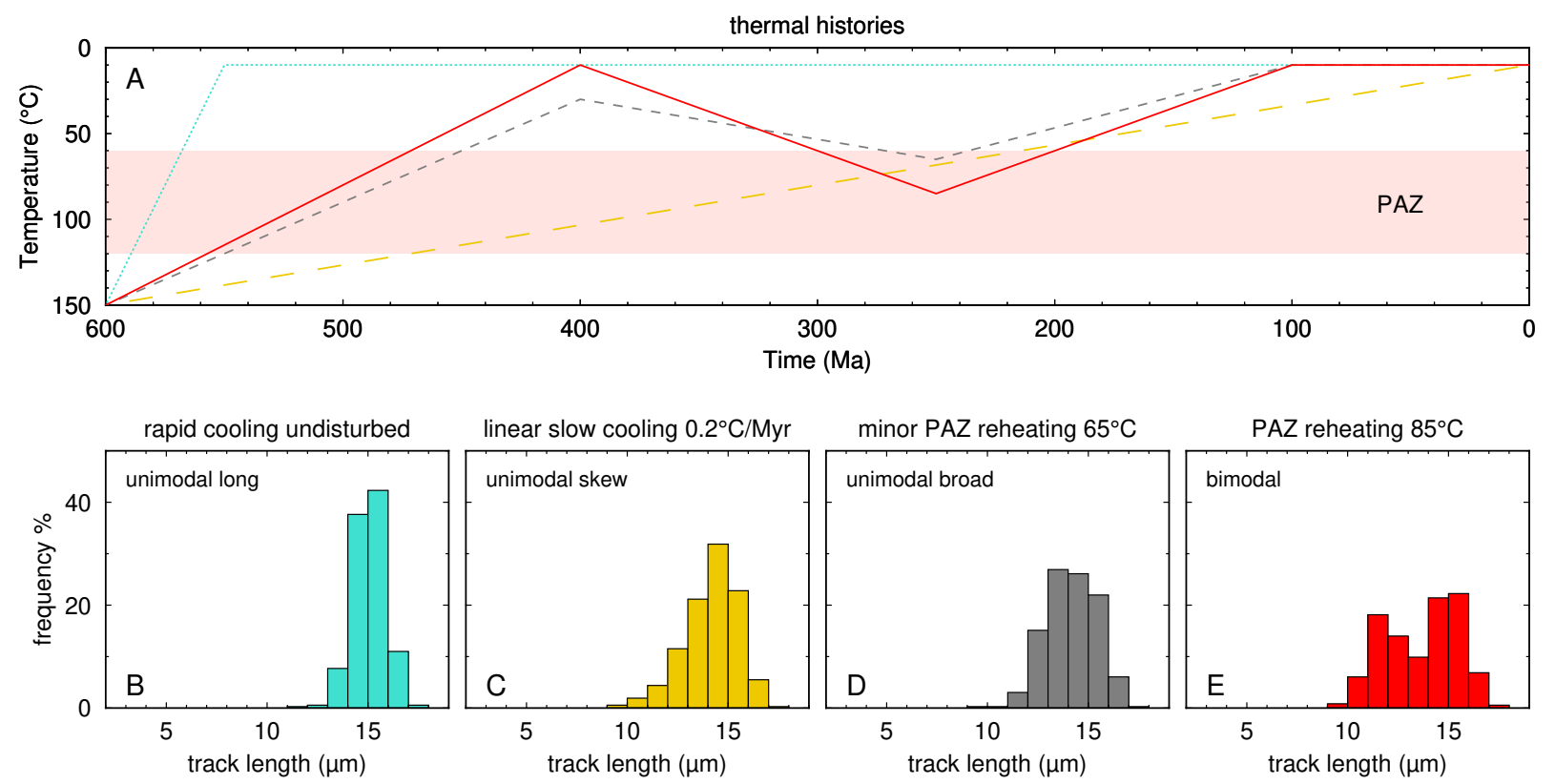

Figure 1: (A) Hypothetical thermal history scenarios and the corresponding c-axis projected track length distributions produced from each $t-T$ path. Rapid cooling (blue dotted line), slow cooling (yellow long dash line), minor PAZ reheating (gray short dash line), and greater PAZ reheating (red solid line). (B) unimodal long track lengths corresponding to rapid cooling and subsequent stasis. (C) unimodal right skew track length distribution typical of simple, slow cooling. (D) unimodal track length distribution that has been shortened and broadened due to reheating to $65^{\circ} \mathrm{C}$. (E) bimodal track length distribution due to a history involving greater reheating to $85^{\circ} \mathrm{C}$.

trying to reconstruct the time-temperature $(t-T)$ histories from these data, the lack of physical geologic constraints to inform modeling is problematic (McDannell and Flowers, 2020; McDannell and Issler, 2021). This is commonly addressed by utilizing whatever geologic information we do have -however, unless samples are taken directly from well-constrained locations (e.g., near basement unconformities), there is typically some degree of regional extrapolation of, or uncertainty in, assumptions about past geologic conditions. In some situations these regional inferences may be warranted, whereas in others they may not, and it is difficult to know which is the case before carrying out modeling. The issue then relates to our ability to resolve more complex thermal histories in the absence of firm geological constraints.

One option to constrain low-temperature histories $\left(<150^{\circ} \mathrm{C}\right)$ is to better exploit the information contained in the horizontal confined track-length distributions provided by the AFT method, as track lengths are sensitive indicators of thermal history style (Crowley, 1985; Gleadow et al., 1986; Duddy et al., 1988; Green et al., 1989). The convention has been for analysts to count the number of spontaneous tracks $\left(\mathrm{N}_{s}\right)$ from up to 20 grains for age determination and measure a minimum of $\sim 50-100$ track lengths to obtain a representative distribution for use in $t-T$ modeling (e.g., Rahn and Seward, 2000; Donelick et al., 2005). While the optimal number of data to collect is dependent upon the geological problem, 100 tracks is generally considered sufficient for statistical reasons and analytical economy (Donelick et al., 2005). For instance, if a volcanic rock is rapidly cooled at or near the surface and is characterized by a long $(>14 \mu \mathrm{m})$, narrow track-length 
distribution (e.g., Gleadow et al., 1986; and our Fig. 1), then 100 track lengths is more than enough data for characterizing the thermal history. The implicit assumption is that at some finite number of tracks, there are diminishing returns regarding the information contained in, and retrievable from, AFT data- which is in principle dependent upon the complexity of the thermal history and the amount of annealing endured by a sample. In the particular case of cratons, histories are complex and often involve slow cooling rates on the order of a few ${ }^{\circ} \mathrm{C} / \mathrm{My}$ (or less) and relatively minor, episodic heating $\left(\sim 60-90^{\circ} \mathrm{C}\right)$ into the PAZ due to burial - thus presenting a challenge for modeling, especially if geologic constraints are lacking.

Here we discuss AFT "super samples" (AFTSS), which are defined as samples where a far greater number of confined track lengths are measured $(\sim 300-700)$ compared to conventional AFT methods. AFTSS have increased resolving power for deciphering complex thermal histories involving partial annealing and multiple reheating events - and can be used to independently deduce past geologic conditions (without the enforcement of many a priori constraints during modeling). Modeling is therefore guided by a heuristic or empirical philosophy regarding 'constraint' placement. While indisputable geologic information should be used if available, it is often not available in cratonic settings. Therefore, we minimize the implementation of constraints (as time-temperature boxes) that force the model to take an predefined path, allowing us to instead examine the ability of the model to independently infer geologically plausible $t-T$ paths from the thermochronologic data alone. Simulations were performed in the Bayesian QTQt software (Gallagher, 2012) to illustrate the benefits of this approach. AFTSS analysis opens up the possibility of enhancing thermal history recovery by maintaining established AFT methodologies but simply increasing the number of track lengths collected for use during $t-T$ inversion.

\section{Time-temperature modeling approach}

Forward and inverse modeling was carried out within a Bayesian modeling framework using the QTQt v. 5.8.0 software (Gallagher, 2012). For the inversion, QTQt implements a reversible jump Markov Chain Monte Carlo (MCMC) algorithm that utilizes various prior information (defining the range of allowable values for parameters such as time and temperature, heating-cooling rate, kinetic parameter variability, i.e., track annealing kinetics, and more specific geological-type constraints such as the depositional age of sedimentary rocks or timing of unconformities). These parameters are randomly sampled and perturbed as individual forward models are iteratively constructed many times, yielding an ensemble of accepted $t-T$ solutions that reproduce the observed data. The criterion for proposed model acceptance in MCMC is based on the combined prior-likelihood-proposal ratio, and simple thermal histories with fewer $t-T$ points are generally preferred over more complex ones if the fit between the predicted and observed data is similar- hence the 
data determine the level of history complexity (Gallagher, 2012). This general approach is also beneficial for assessing the resolving power of low-temperature thermochronometric data with or without user-specified constraints (McDannell and Issler, 2021).

QTQt model runs were setup with the same general prior for the thermal history: $300 \pm 300 \mathrm{Ma}$ and 75 $\pm 75^{\circ} \mathrm{C}\left(70 \pm 70^{\circ} \mathrm{C}\right.$ for real data; see below) and a modern surface temperature of $10 \pm 10^{\circ} \mathrm{C}(\mathrm{maximum}$ allowed heating/cooling rate of $\left.3^{\circ} \mathrm{C} / \mathrm{My}\right)^{1}$. The annealing model of Ketcham et al. (1999) was used with the $\mathrm{r}_{m r 0}$ kinetic parameter and track length c-axis projection. The apatite composition was specified as common fluorapatite with a $\mathrm{r}_{m r 0}$ value of 0.84 (or $0.0 \mathrm{eCl}$ ) for synthetic data. Apatite composition was allowed to vary within uncertainty for the real AFT data discussed below and the initial track length was calculated based on composition. Models were run for a total of 500,000 iterations, with an initial burn-in of 100,000 iterations. The 400,000 MCMC post burn-in iterations were used to approximate the posterior probability distribution of model parameters. We also incorporated a recently introduced option in QTQt to reject a more complex proposed model (or accept a simpler proposed model explicitly if the data fit does not change). This is achieved by monitoring the likelihood during proposed addition or removal of a $t-T$ point - if a point is added (i.e., increasing $t-T$ path complexity) and the likelihood remains the same, then the proposal model is rejected, whereas the opposite occurs for the removal of a point. This option inherently reduces $t-T$ uncertainty and penalizes complexity more heavily than the general algorithm presented in Gallagher (2012), providing a lower bound on the complexity required to best explain the observations. It should be noted that the final population of accepted thermal history models is of course conditional on this assumption and as such should be considered as a conditional posterior distribution.

\section{How many track lengths do we need to resolve complex histories?}

\subsection{Synthetic resolution tests}

We consider how the number of confined track lengths affects our ability to reconstruct the thermal history. We initially examined whether a typical AFT analysis with $100 \pm 50$ track lengths contains enough information for cratonic thermal history reconstruction without imposing numerous model assumptions. We may then ask how many tracks are necessary for adequate $t-T$ resolution? While these questions are specific to the examples discussed here, the requirement of a representative number of track lengths is axiomatic to any AFT thermal history reconstruction and may generally apply to other regions that experienced similar protracted histories involving episodic reheating and partial track annealing from sedimentary burial. We first

\footnotetext{
${ }^{1}$ These limits were imposed to prevent extreme temperature fluctuations and $t-T$ paths that are unlikely for this geologic setting. The allowance of higher rates during tests did not change the form of the model thermal histories.
} 
use synthetic AFT data to explore a simple case and so avoid the problems inherent to natural samples with unknown histories. We use a thermal history in which the maximum reheating temperature is relatively low but still high enough to cause some annealing of the tracks present at that time. The aim is to demonstrate the sensitivity of the length distribution (and the number of tracks defining it) to subtle reheating events and the our ability to recover the thermal history with different amounts of track-length data.
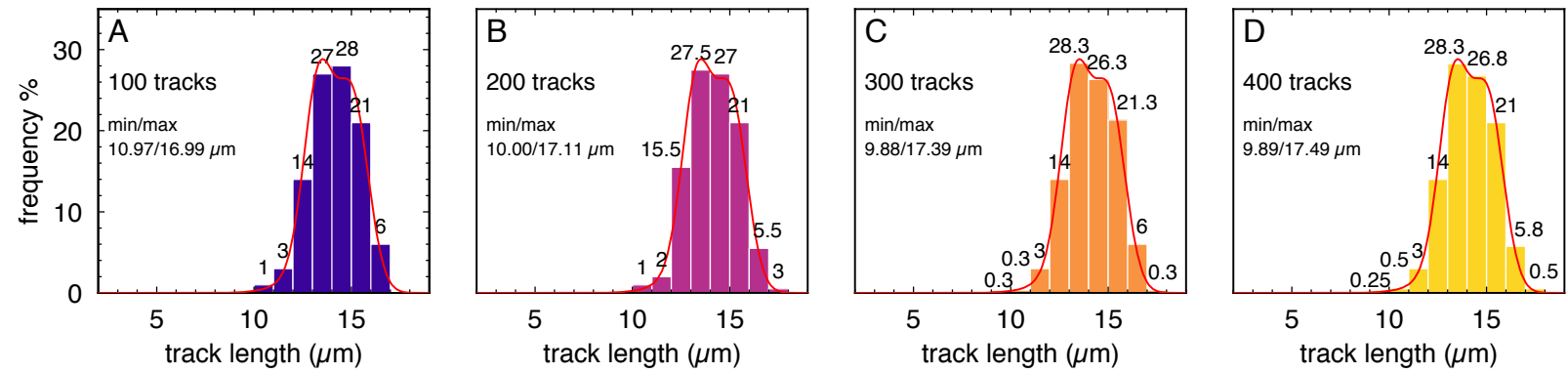

Figure 2: Track length distributions derived from forward modeling dashed gray $t-T$ path in Figure 1 (i.e., broad unimodal with heating to $65^{\circ} \mathrm{C}$ ). Red curve is the true predicted distribution. The number of tracks that define the predicted distribution were randomly drawn and increased from 100 to 400 and are shown as histograms with $1 \mu \mathrm{m}$ bins. (A) 100 tracks. (B) 200 tracks. (C) 300 tracks. (D) 400 tracks. True distributions in B-D were normalized to panel A. Values above histogram bars are the percent of total tracks in each bin (rounded $0.1 \%$ ) that define the distribution.

The reheating history shown in Figure 1A (dashed gray path) was forward modelled to produce synthetic AFT data (Fig. 2). The AFT age data were held constant, whereas the number of track lengths sampled from the predicted length distribution was progressively increased from 100 to 400. Increasing the number of tracks represented in the histograms improves characterization of subtle features of the predicted distribution, namely the tails and the 'shoulder' at 14-15 $\mu \mathrm{m}$ (Fig. 2). We are demonstrating that with a greater number of tracks, we more accurately represent the 'true' length distribution (Fig. 2). These synthetic samples were then inverted in an attempt to recover the true history used to generate the track data (Fig. 3). While these results are conditional on rejecting more complex models - 100 measured track lengths are not enough data to fully resolve the $t-T$ path. These models illustrate that $>200$ track lengths are required to properly capture the details of the thermal history in a case involving minor thermal annealing. Inverse models with a greater number of tracks improved the resolution of the early cooling episode, which is to be expected since more tracks experienced this cooling event-however, as more tracks are utilized, the reheating event is better resolved by a larger proportion of the accepted model paths (Fig. 3). A general point learned from this demonstration is that if the thermal history is complex, then we will likely require more track lengths to properly define the (similarly complex) distribution for modeling. We examined these concepts further using real AFT data from the Canadian Shield. 

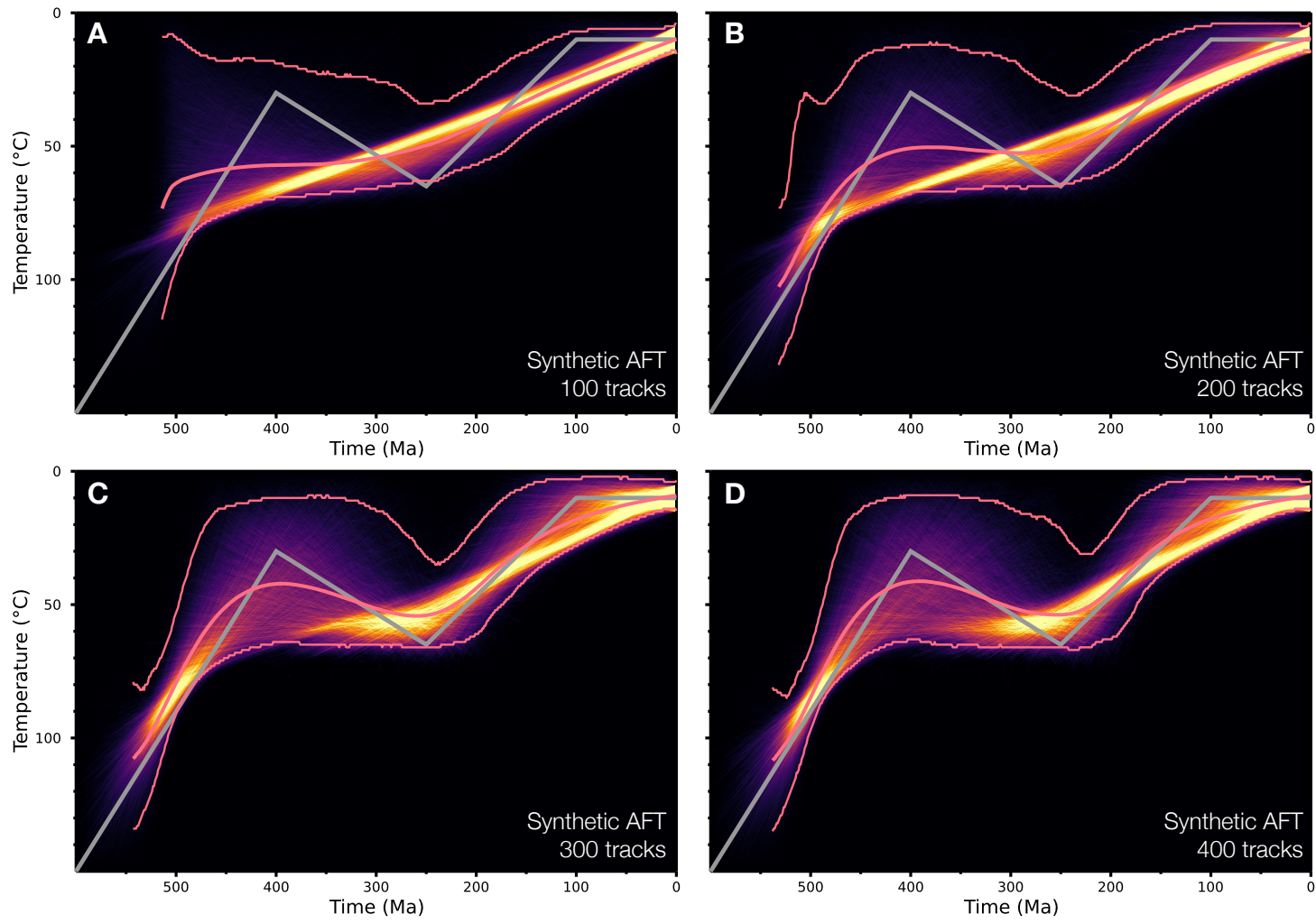

Figure 3: Inverse QTQt models using synthetic AFT data derived from the dashed gray $t-T$ path in Fig. 1A (lengths in Fig. 1D). Results are shown as heat maps of $t-T$ path density, where brighter colors are higher relative posterior probability. The difference between each model going from $\mathrm{A}$ to $\mathrm{D}$ is the increased number of tracks that define the true predicted distribution. (A) results for 100 tracks; (B) results for 200 tracks; (C) results for 300 tracks; (D) results for 400 tracks. The gray path is the true history and the pink lines are the QTQt Expected model with $95 \%$ credible interval. The latter model is the average of the marginal distribution and is shown as a summary of all accepted post burn-in solutions and does not represent an individual history sampled during the inversion. Figure S1 in the $S I$ shows forward models of the same $t-T$ path for a typical endmember fluorapatite where the thermal peak is progressively increased from $65^{\circ} \mathrm{C}$ (shown here) to $115^{\circ} \mathrm{C}$ in $10^{\circ} \mathrm{C}$ increments. This demonstrates how the AFT central age and track-length distribution evolve with increased heating into the PAZ until the sample is thermally reset near $\sim 110^{\circ} \mathrm{C}$.

\subsection{Case study: Hearne Domain and Trans-Hudson Orogen, Canadian Shield}

Two crystalline basement samples were collected from the central Canadian Shield that have some reliable, yet limited geologic information (described below) to support thermal history modeling. The Hearne Domain lies in the Churchill Province of the shield (Fig. 4) and is primarily comprised of Neoarchean granitoids, greenstones, metasedimentary and volcanic rocks, and Paleoproterozoic granites that flank the $c$. 1900-1800 Ga Tran-Hudson Orogen (THO) basement to the south (Hoffman, 1989; Fig. 4) and the Paleozoic-Mesozoic Hudson Bay sedimentary basin to the east (e.g., Pinet et al., 2013). This area is considered to have generally been tectonically stable since $c$. $1650 \mathrm{Ma}$ (Rainbird et al., 2007) following the Trans-Hudson orogeny. The Hearne sample (97-10-365) is from the exposed granodiorite basement within the Seal River Fold Belt. This location is at the erosional edge of the Hudson Bay Precambrian unconformity at the mouth of the Seal River in northeastern Manitoba. The THO sample was collected from a foliated biotite tonalite from Stephens Lake, $\sim 28 \mathrm{~km}$ from the Paleozoic unconformity in Manitoba. Regional geologic context for the Phanerozoic, with respect to the sample locations, is as follows: 
- The preserved onshore basal Paleozoic section of the Hudson Bay Basin is the upper Ordovician Portage Chute Formation (c. $450 \mathrm{Ma}$ ) of the Bad Cache Rapids Group (e.g., Lavoie et al., 2019, for summary).

- The Moose River Basin ( 700-1000 km to the SE; Fig. 4) contains Upper Ordovician through Upper Devonian strata with a major unconformity overlain by erosional remnants of minor Middle Jurassic and unconformable (Albian and Aptian?) Cretaceous rocks (Norris, 1977; Telford and Long, 1986; Norris, 1993; Pinet et al., 2013).

- The $c .180-170$ Ma hypabyssal facies kimberlites in the Attawapiskat vicinity of the Moose River Basin were erupted subaerially through basement and Paleozoic cover (Sage, 2000, for review).

- The Williston Basin lies to the southwest of our samples (Fig. 4) and contains thick basin fill of $>4 \mathrm{~km}$ due to deposition during most of the Phanerozoic (Burrus et al., 1996), beginning with the platform onlap of the Sauk sequence (Sloss, 1963; Burgess, 2019).

- The INCO-Winisk \#49204 borehole ( 500-700 km to the SE; Fig. 4) contains palynological evidence of Aptian-Turonian sediment recycling and sediments preserved at $\sim 70 \mathrm{~m}$ depth of Miocene age $(c$. 23-5 Ma) unconformably overlying the Paleozoic section (Galloway et al., 2012).

This information suggests that Precambrian basement was exposed by $450 \mathrm{Ma}$. An interval of regional subaerial exposure during the Early-Middle Jurassic was possible, followed by deposition during the Cretaceous and exhumation by approximately Miocene. There is also the question of whether this part of the currently exposed shield basement was buried during deposition of the Hudson Bay sequence. We present our new analytical results, which are then modelled to assess whether our AFTSS data can yield thermal histories that are independently consistent with the accepted regional geological evolution.

\section{Apatite fission track and electron microprobe methods and results}

Apatite grains were double-dated (AFT and U-Pb) by the LA-ICPMS method (Chew and Donelick, 2012; Cogné et al., 2020). The modified $\zeta$-calibration approach was utilized with the Durango and McClure Mountain age standards for FT and U-Pb data acquisition. The AFT pooled age obtained in analytical sessions for Durango was $31.4 \pm 1.6 \mathrm{Ma}(2 \sigma)$ and $256 \pm 14 \mathrm{Ma}$ for McClure Mtn. apatite. The weighted mean U-Pb age of McClure Mtn. apatite was $525 \pm 27 \mathrm{Ma}(2 \sigma)$. All ages are in agreement with accepted previously published values (see Chew and Donelick, 2012). All analytical methods are the same as those discussed in McDannell et al. (2019a) and McDannell et al. (2019b).

Single guided laser-ablation spots were chosen within minimized grain counting areas to avoid potential U zonation and all analytical results are shown in Table 1 and Table 2. The high $\mathrm{N}_{s}$ track densities make $\mathrm{U}$ 


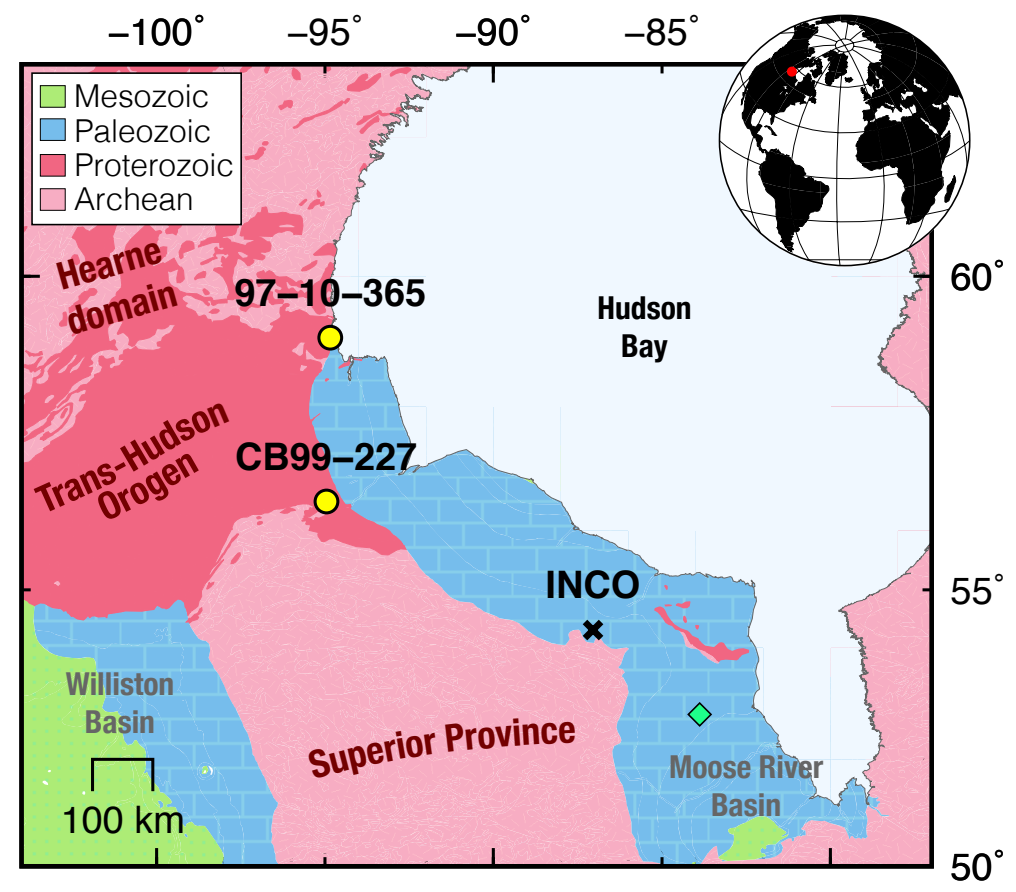

Figure 4: Simplified geologic map of the central Canadian Shield near Hudson Bay, modified from Wheeler et al. (1997). AFT sample locations are yellow points. Trans-Hudson Orogen (THO; c. 1.9-1.8 Ga) rocks are within the solid dark red area of the map. The Hudson Bay Basin Paleozoic section outcrops (blue) along the THO and W. Superior Province. Green diamond is location of the Attawapiskat kimberlite field. INCO is the borehole discussed in Galloway et al. (2012); refer to the text for discussion.

zoning on the etched grain surface easily detectable, and neither example showed evidence for strong zoning. One procedural difference for the data discussed here is that the AFT samples were split into two aliquots, and thus different grain mounts. The first aliquot was analysed using the typical, faster LA-ICPMS operation where track lengths are measured on all grains from which an age was measured and also other (undated) grains. Whereas, the second aliquots had track lengths measured only from grains that had ages measured. The latter approach is more time consuming, since all lengths within a count area are measured to avoid measurement bias - in this case resulting in a large number of collected track lengths due to the high $\mathrm{N}_{s}$ tracks present. The $\mathrm{N}_{s}$ counts alone for our two samples totalled nearly 26,800 and the number of measured track lengths was 1,365 - for comparison, this is $\sim 10-100 \times$ the amount of track/count data acquired with respect to a conventional AFT analysis.

Electron probe microanalysis (EPMA) was carried out using a single-spot per grain on the AFT mounts at Washington State University for the elements: Ca, P, F, Cl, Na, Mg, Mn, Fe, Sr, Y, La, Ce, S, and OH estimated by difference. The second AFT aliquots included Si and had two EPMA spots analysed, one near the LA pit, and the other located in a different area of the grain to assess potential compositional heterogeneity. Complete EPMA data are provided in the Supplementary Information $(S I)$, and are summarized in Table 1 and Table 2. Elemental analyses with wt\% oxide totals are $98.8 \pm 1.8 \%$ for 225 analyses (including 
$\mathrm{OH}$ estimation) and suggest near endmember F-apatite for both samples with insignificant variation in composition. The few grains with low totals $<97 \%$ are flagged in the supplemental dataset and should be used with caution for any petrogenetic interpretation. The elemental data are combined into a single value, $\mathrm{r}_{m r 0}$, for approximating the annealing kinetics of the AFT data during inverse modeling. The $\mathrm{r}_{m r 0}$ values were calculated using the Carlson et al. (1999) equation and apatite stoichiometric calculations for EPMA data from Ketcham (2015) and were converted to 'effective Cl' values (see McDannell and Issler, 2021 and Issler et al., 2021 for discussion). Effective $\mathrm{Cl}$ of 0.0 apfu is indicative of endmember fluorapatite and negative eCl indicates an extrapolation of the Carlson et al. (1999) $\mathrm{r}_{m r 0^{-}} \mathrm{Cl}$ relation for $\mathrm{r}_{m r 0}$ values $>0.84$.

The AFT central age for sample $97-10-365$ is $512 \pm 18 \mathrm{Ma}\left(1 \sigma, \mathrm{n}=63\right.$, age dispersion $=26 \%, \mathrm{P}\left(\chi^{2}\right)=$ $0.0)$ and the central age for sample CB99-227 is $486 \pm 22 \mathrm{Ma}\left(1 \sigma, \mathrm{n}=50\right.$, age dispersion $=30 \%, \mathrm{P}\left(\chi^{2}\right)$ $=0.0$ ). Sample 97-10-365 has an overall conventional mean track length of $12.01 \pm 1.75 \mu \mathrm{m}$ and c-axis projected mean length of $13.63 \pm 1.02 \mu \mathrm{m}(\mathrm{n}=709)$, whereas sample CB99-227 has a conventional mean track length of $11.81 \pm 1.67 \mu \mathrm{m}$ and c-axis projected mean length of $13.53 \pm 0.94 \mu \mathrm{m}(\mathrm{n}=656)$. The samples overlap in central age and mean track length at $1 \sigma$, which could qualitatively indicate a similar or shared thermal history given their proximity to one another. In spite of $\chi^{2}$ failures for both samples, there is no clear indication of multiple kinetic age populations due to compositional variation. The samples exhibit high age scatter and a weak negative trend between single-grain age and uranium (i.e., ${ }^{238} \mathrm{U} /{ }^{43} \mathrm{Ca}$ ratio), apparently indicative of 'radiation-enhanced annealing' (REA) encountered in AFT data from Precambrian rocks (Hendriks and Redfield, 2006; McDannell et al., 2019a). While recent laboratory experiments confirm REA is a real phenomenon, it is evidently not a concern for apatite (Li et al., 2021). Outstanding questions relate to how and if time plays a role in this process with respect to radiation damage and fission-track accumulation for ancient apatites, or if over long timescales, accumulated alpha-radiation damage lowers thermal annealing resistance (Ketcham, 2019; McDannell et al., 2019a). Here the data were interpreted as overdispersed single populations. High dispersion is likely attributable to a continuous distribution of ages rather than the typically assumed discrete age components (Vermeesch, 2019)—which may be at least partially due to the protracted slow cooling (and differential annealing) these samples experienced, the greater number of analyses relative to conventional AFT of $\leq 20$ age grains, and higher relative LA-ICPMS age precision (Ketcham et al., 2018; Vermeesch, 2019; McDannell, 2020).

\section{Canadian Shield time-temperature inversions}

We examined the ability of the AFTSS data to resolve the shield thermal history and QTQt model results are shown in Figure 5 as heat maps of $t-T$ path density, where brighter colors are higher relative posterior 
Table 1: Apatite fission-track data for sample 97-10-365, Hearne Domain.

\begin{tabular}{|c|c|c|c|c|c|c|c|c|c|c|c|c|c|c|c|c|c|}
\hline $\mathbf{N}_{s}$ & $\begin{array}{c}\text { Area }\left(\Omega_{i}\right) \\
\left(\mathbf{c m}^{2}\right)\end{array}$ & ${ }^{238} \mathbf{U} /{ }^{43} \mathrm{Ca}$ & $1 \sigma$ & $\mathbf{P}_{i} \Omega_{i}$ & $\sigma \mathbf{P}_{i}^{2} \Omega_{i}^{2}$ & $\begin{array}{c}\text { AFT age } \dagger \\
\text { (Ma) }\end{array}$ & $\begin{array}{c}1 \sigma \\
(\mathrm{Ma})\end{array}$ & $\begin{array}{l}\mathbf{D}_{\text {par }} \\
(\mu \mathrm{m})\end{array}$ & $\begin{array}{c}\mathbf{F} \star \\
(\text { apfu) }\end{array}$ & $\begin{array}{c}\mathrm{Cl} \star \\
(\text { apfu) }\end{array}$ & $\begin{array}{c}\mathrm{OH} \star \\
\text { (apfu) }\end{array}$ & $\begin{array}{l}\mathbf{r}_{m r 0} \\
\mathbf{1 9 9 9}\end{array}$ & $\begin{array}{c}\mathrm{eCl}(\mathrm{A}) \\
\text { (apfu) }\end{array}$ & $\begin{array}{c}\text { eCl (B) } \\
\text { (apfu) }\end{array}$ & $\begin{array}{c}\mathrm{U}-\mathrm{Pb} \ddagger \\
\text { age (Ma) }\end{array}$ & $\begin{array}{c}2 \sigma \\
\text { (Ma) }\end{array}$ & $\begin{array}{c}\text { aliquot } \\
\text { grain }\end{array}$ \\
\hline 97 & $2.91 \mathrm{E}-05$ & $2.77 \mathrm{E}-02$ & $9.38 \mathrm{E}-03$ & $8.06 \mathrm{E}-07$ & $7.46 \mathrm{E}-14$ & 926 & 328 & 2.09 & 1.69 & 0.00 & 0.30 & 0.840 & 0.001 & - & - & - & a1-1 \\
\hline 73 & $2.91 \mathrm{E}-05$ & $3.01 \mathrm{E}-02$ & $2.79 \mathrm{E}-03$ & $8.76 \mathrm{E}-07$ & $6.60 \mathrm{E}-15$ & 655 & 98 & 1.96 & 1.55 & 0.00 & 0.45 & 0.843 & -0.007 & - & - & - & a1-2 \\
\hline 80 & $2.91 \mathrm{E}-05$ & $4.14 \mathrm{E}-02$ & $3.23 \mathrm{E}-03$ & $1.21 \mathrm{E}-06$ & $8.83 \mathrm{E}-15$ & 527 & 72 & 1.99 & 1.58 & 0.01 & 0.42 & 0.842 & -0.005 & - & - & - & a1-3 \\
\hline 426 & $5.82 \mathrm{E}-05$ & $1.49 \mathrm{E}-01$ & $9.66 \mathrm{E}-03$ & 8.65E-06 & $3.17 \mathrm{E}-13$ & 395 & 33 & 1.71 & 1.59 & 0.01 & 0.40 & 0.838 & 0.005 & - & - & - & a1-4 \\
\hline 162 & $3.88 \mathrm{E}-05$ & $7.08 \mathrm{E}-02$ & $4.49 \mathrm{E}-03$ & $2.75 \mathrm{E}-06$ & $3.04 \mathrm{E}-14$ & 470 & 48 & 1.83 & 1.52 & 0.00 & 0.47 & 0.838 & 0.008 & - & - & - & a1-5 \\
\hline 65 & $2.91 \mathrm{E}-05$ & $3.69 \mathrm{E}-02$ & $1.07 \mathrm{E}-03$ & $1.07 \mathrm{E}-06$ & $9.79 \mathrm{E}-16$ & 482 & 62 & 1.62 & 1.59 & 0.00 & 0.41 & 0.840 & 0.002 & - & 2155 & 471 & a1-6 \\
\hline 94 & $1.94 \mathrm{E}-05$ & $4.99 \mathrm{E}-02$ & $1.72 \mathrm{E}-03$ & $9.70 \mathrm{E}-07$ & $1.12 \mathrm{E}-15$ & 756 & 83 & 1.86 & - & - & - & - & - & - & - & - & a1- $7^{*}$ \\
\hline 64 & $2.43 \mathrm{E}-05$ & $1.67 \mathrm{E}-01$ & $4.61 \mathrm{E}-02$ & 4.05E-06 & $1.25 \mathrm{E}-12$ & 130 & 39 & 1.67 & 1.60 & 0.00 & 0.39 & 0.845 & -0.016 & - & - & - & a1-8* \\
\hline 126 & $3.40 \mathrm{E}-05$ & 4.73E-02 & $1.43 \mathrm{E}-03$ & $1.61 \mathrm{E}-06$ & $2.37 \mathrm{E}-15$ & 618 & 59 & 1.94 & 1.71 & 0.00 & 0.29 & 0.844 & -0.011 & - & 2424 & 561 & a1-9 \\
\hline 59 & $1.94 \mathrm{E}-05$ & $5.24 \mathrm{E}-02$ & $3.44 \mathrm{E}-03$ & $1.02 \mathrm{E}-06$ & $4.45 \mathrm{E}-15$ & 463 & 68 & 1.98 & 1.63 & 0.01 & 0.37 & 0.845 & -0.016 & - & 2479 & 1347 & a1-10 \\
\hline 264 & $3.11 \mathrm{E}-05$ & $1.85 \mathrm{E}-01$ & $4.20 \mathrm{E}-03$ & $5.73 \mathrm{E}-06$ & $1.70 \mathrm{E}-14$ & 370 & 25 & 1.97 & 1.58 & 0.11 & 0.31 & 0.814 & 0.071 & - & 2400 & 299 & a1-11 \\
\hline 104 & $4.85 \mathrm{E}-05$ & $4.14 \mathrm{E}-02$ & $1.09 \mathrm{E}-03$ & $2.01 \mathrm{E}-06$ & $2.79 \mathrm{E}-15$ & 415 & 43 & 1.97 & 1.62 & 0.01 & 0.37 & 0.842 & -0.005 & - & 2321 & 413 & a1-12 \\
\hline 149 & $3.40 \mathrm{E}-05$ & $3.06 \mathrm{E}-02$ & 7.03E-04 & $1.04 \mathrm{E}-06$ & $5.70 \mathrm{E}-16$ & 1087 & 94 & 1.86 & 1.69 & 0.00 & 0.31 & 0.849 & -0.027 & - & 1980 & 324 & a1-13 \\
\hline 45 & $2.33 \mathrm{E}-05$ & $2.83 \mathrm{E}-02$ & $6.74 \mathrm{E}-04$ & $6.59 \mathrm{E}-07$ & $2.46 \mathrm{E}-16$ & 541 & 82 & 1.88 & 1.77 & 0.01 & 0.22 & 0.853 & -0.038 & & 1995 & 419 & a1-14 \\
\hline 106 & $2.91 \mathrm{E}-05$ & $6.24 \mathrm{E}-02$ & $1.45 \mathrm{E}-03$ & $1.82 \mathrm{E}-06$ & $1.79 \mathrm{E}-15$ & 466 & 47 & 1.93 & 1.65 & 0.00 & 0.35 & 0.845 & -0.014 & - & 2385 & 402 & a1-15 \\
\hline 124 & $3.88 \mathrm{E}-05$ & $5.28 \mathrm{E}-02$ & $1.20 \mathrm{E}-03$ & $2.05 \mathrm{E}-06$ & $2.17 \mathrm{E}-15$ & 482 & 45 & 1.88 & 1.73 & 0.00 & 0.26 & 0.844 & -0.012 & - & 2080 & 364 & a1-16 \\
\hline 118 & 2.43E-05 & $5.32 \mathrm{E}-02$ & $1.39 \mathrm{E}-03$ & $1.29 \mathrm{E}-06$ & $1.14 \mathrm{E}-15$ & 715 & 70 & 2.04 & 1.60 & 0.00 & 0.40 & 0.844 & -0.012 & - & 2464 & 498 & a1-17 \\
\hline 103 & 2.43E-05 & $3.65 \mathrm{E}-02$ & $1.02 \mathrm{E}-03$ & $8.86 \mathrm{E}-07$ & $6.09 \mathrm{E}-16$ & 896 & 93 & 2.08 & 1.62 & 0.01 & 0.37 & 0.846 & -0.017 & - & 2107 & 477 & a1-18 \\
\hline 101 & $3.40 \mathrm{E}-05$ & $3.95 \mathrm{E}-02$ & $9.96 \mathrm{E}-04$ & $1.34 \mathrm{E}-06$ & $1.14 \mathrm{E}-15$ & 595 & 62 & 1.82 & 1.62 & 0.01 & 0.38 & 0.841 & -0.002 & - & 2526 & 460 & a1-19 \\
\hline 54 & $2.91 \mathrm{E}-05$ & $3.89 \mathrm{E}-02$ & $1.44 \mathrm{E}-03$ & $1.13 \mathrm{E}-06$ & $1.75 \mathrm{E}-15$ & 382 & 54 & 1.65 & 1.69 & 0.00 & 0.31 & 0.847 & -0.021 & - & 2497 & 596 & a1-20 \\
\hline 97 & $2.91 \mathrm{E}-05$ & $3.03 \mathrm{E}-02$ & $1.40 \mathrm{E}-03$ & $8.83 \mathrm{E}-07$ & $1.66 \mathrm{E}-15$ & 850 & 96 & 2.14 & 1.65 & 0.01 & 0.35 & 0.840 & 0.000 & - & - & - & a1-21 \\
\hline 81 & $2.33 \mathrm{E}-05$ & $2.66 \mathrm{E}-02$ & $1.27 \mathrm{E}-03$ & $6.19 \mathrm{E}-07$ & 8.73E-16 & 1001 & 122 & 1.80 & 1.50 & 0.02 & 0.48 & 0.827 & 0.038 & - & - & - & a1-22 \\
\hline 345 & $4.37 \mathrm{E}-05$ & $1.39 \mathrm{E}-01$ & $3.39 \mathrm{E}-03$ & $6.06 \mathrm{E}-06$ & $2.20 \mathrm{E}-14$ & 455 & 28 & 2.03 & 1.76 & 0.00 & 0.24 & 0.848 & -0.023 & - & - & - & a1-23 \\
\hline 164 & $4.85 \mathrm{E}-05$ & $4.80 \mathrm{E}-02$ & $1.49 \mathrm{E}-03$ & 2.33E-06 & $5.25 \mathrm{E}-15$ & 558 & 48 & 1.75 & 1.57 & 0.00 & 0.43 & 0.844 & -0.010 & - & - & - & a1-24 \\
\hline 96 & $3.40 \mathrm{E}-05$ & $5.01 \mathrm{E}-02$ & $1.73 \mathrm{E}-03$ & $1.70 \mathrm{E}-06$ & $3.45 \mathrm{E}-15$ & 450 & 49 & 2.03 & - & - & - & - & - & - & 2471 & 593 & a1-25 \\
\hline 293 & $3.88 \mathrm{E}-05$ & $1.50 \mathrm{E}-01$ & $4.43 \mathrm{E}-03$ & $5.82 \mathrm{E}-06$ & $2.95 \mathrm{E}-14$ & 404 & 27 & 1.99 & - & - & - & - & - & - & 2238 & 328 & a2-1 \\
\hline 472 & $5.82 \mathrm{E}-05$ & 7.83E-02 & $2.54 \mathrm{E}-03$ & $4.56 \mathrm{E}-06$ & $2.19 \mathrm{E}-14$ & 804 & 47 & 1.86 & 1.55 & 0.00 & 0.45 & 0.838 & 0.006 & 0.006 & 2205 & 518 & a2-2 \\
\hline 446 & $5.82 \mathrm{E}-05$ & $1.20 \mathrm{E}-01$ & $2.84 \mathrm{E}-03$ & $6.98 \mathrm{E}-06$ & $2.73 \mathrm{E}-14$ & 508 & 28 & 1.43 & - & - & - & - & - & - & 1736 & 383 & a2-3 \\
\hline 304 & $5.82 \mathrm{E}-05$ & $5.22 \mathrm{E}-02$ & $9.33 \mathrm{E}-04$ & $3.04 \mathrm{E}-06$ & $2.95 \mathrm{E}-15$ & 779 & 49 & 1.79 & 1.52 & 0.01 & 0.471 & 0.841 & -0.002 & 0.000 & 2193 & 384 & a2-4 \\
\hline 228 & $5.82 \mathrm{E}-05$ & $5.86 \mathrm{E}-02$ & $1.15 \mathrm{E}-03$ & $3.41 \mathrm{E}-06$ & $4.48 \mathrm{E}-15$ & 531 & 38 & 1.70 & 1.65 & 0.01 & 0.35 & 0.841 & -0.001 & -0.001 & 2088 & 528 & a2-5 \\
\hline 274 & $2.91 \mathrm{E}-05$ & $1.64 \mathrm{E}-01$ & $3.12 \mathrm{E}-03$ & $4.77 \mathrm{E}-06$ & $8.24 \mathrm{E}-15$ & 458 & 30 & 2.06 & 1.51 & 0.01 & 0.48 & 0.839 & 0.003 & 0.028 & 2242 & 376 & a2-6 \\
\hline 137 & $3.88 \mathrm{E}-05$ & $7.85 \mathrm{E}-02$ & $1.58 \mathrm{E}-03$ & $3.05 \mathrm{E}-06$ & $3.76 \mathrm{E}-15$ & 362 & 32 & 1.61 & 1.68 & 0.00 & 0.31 & 0.848 & -0.025 & -0.029 & 1724 & 305 & a2-7 \\
\hline 446 & $4.85 \mathrm{E}-05$ & $1.80 \mathrm{E}-01$ & $2.99 \mathrm{E}-03$ & $8.73 \mathrm{E}-06$ & $2.10 \mathrm{E}-14$ & 409 & 22 & 1.53 & 1.71 & 0.00 & 0.28 & 0.850 & & -0.029 & 2172 & 249 & a2-8 \\
\hline 119 & $3.40 \mathrm{E}-05$ & $4.78 \mathrm{E}-02$ & $1.42 \mathrm{E}-03$ & 1.63E-06 & $2.33 \mathrm{E}-15$ & 579 & 57 & 1.60 & 1.62 & 0.02 & 0.37 & 0.842 & -0.006 & -0.004 & 2134 & 307 & a2-9 \\
\hline 255 & $4.85 \mathrm{E}-05$ & 7.41E-02 & $1.48 \mathrm{E}-03$ & $3.59 \mathrm{E}-06$ & $5.15 \mathrm{E}-15$ & 562 & 38 & 1.72 & 1.66 & 0.01 & 0.33 & 0.837 & 0.008 & 0.000 & 2075 & 297 & a2-10 \\
\hline 104 & $3.88 \mathrm{E}-05$ & $3.81 \mathrm{E}-02$ & $9.23 \mathrm{E}-04$ & $1.48 \mathrm{E}-06$ & $1.28 \mathrm{E}-15$ & 557 & 57 & 2.02 & 1.55 & 0.01 & 0.44 & 0.835 & 0.015 & -0.021 & 1949 & 356 & a2-11 \\
\hline 511 & $5.82 \mathrm{E}-05$ & $1.82 \mathrm{E}-01$ & $3.68 \mathrm{E}-03$ & $1.06 \mathrm{E}-05$ & $4.59 \mathrm{E}-14$ & 387 & 20 & 1.70 & 1.69 & 0.01 & 0.30 & 0.848 & -0.023 & 0.018 & 2292 & 319 & a2-12 \\
\hline 699 & $7.77 \mathrm{E}-05$ & $1.59 \mathrm{E}-01$ & $3.33 \mathrm{E}-03$ & $1.24 \mathrm{E}-05$ & $6.69 \mathrm{E}-14$ & 452 & 21 & 1.88 & 1.51 & 0.00 & 0.49 & 0.839 & 0.003 & -0.002 & 2176 & 312 & a2-13 \\
\hline 216 & $2.91 \mathrm{E}-05$ & $1.06 \mathrm{E}-01$ & $2.36 \mathrm{E}-03$ & $3.08 \mathrm{E}-06$ & $4.72 \mathrm{E}-15$ & 555 & 41 & 1.54 & 1.79 & 0.01 & 0.20 & 0.844 & -0.010 & 0.014 & 2236 & 447 & a2-14 \\
\hline 61 & $3.88 \mathrm{E}-05$ & $4.24 \mathrm{E}-02$ & $9.62 \mathrm{E}-04$ & $1.65 \mathrm{E}-06$ & $1.39 \mathrm{E}-15$ & 300 & 39 & 1.72 & 1.71 & 0.00 & 0.28 & 0.848 & -0.024 & -0.017 & 2126 & 646 & a2-15 \\
\hline 210 & $4.85 \mathrm{E}-05$ & $7.83 \mathrm{E}-02$ & $1.72 \mathrm{E}-03$ & $3.80 \mathrm{E}-06$ & $6.96 \mathrm{E}-15$ & 442 & 33 & 1.79 & 1.52 & 0.00 & 0.48 & 0.837 & 0.011 & -0.012 & 1427 & 347 & a2-16 \\
\hline 452 & $4.85 \mathrm{E}-05$ & $2.09 \mathrm{E}-01$ & $4.77 \mathrm{E}-03$ & $1.01 \mathrm{E}-05$ & $5.35 \mathrm{E}-14$ & 359 & 20 & 1.60 & 1.52 & 0.01 & 0.48 & 0.832 & 0.024 & -0.021 & 1674 & 273 & a2-17 \\
\hline 248 & $3.49 \mathrm{E}-05$ & $1.34 \mathrm{E}-01$ & $2.54 \mathrm{E}-03$ & $4.68 \mathrm{E}-06$ & $7.86 \mathrm{E}-15$ & 424 & 29 & 1.70 & 1.57 & 0.01 & 0.42 & 0.843 & -0.007 & -0.024 & 1527 & 275 & a2-18 \\
\hline 155 & $4.37 \mathrm{E}-05$ & $8.41 \mathrm{E}-02$ & $1.68 \mathrm{E}-03$ & $3.68 \mathrm{E}-06$ & $5.39 \mathrm{E}-15$ & 340 & 29 & 1.56 & 1.58 & 0.01 & 0.41 & 0.842 & -0.005 & 0.001 & 1852 & 381 & a2-19 \\
\hline 252 & $2.91 \mathrm{E}-05$ & $1.51 \mathrm{E}-01$ & $2.46 \mathrm{E}-03$ & $4.39 \mathrm{E}-06$ & $5.12 \mathrm{E}-15$ & 458 & 31 & 1.77 & 1.63 & 0.07 & 0.30 & 0.828 & 0.035 & -0.027 & 1759 & 219 & a2-20 \\
\hline 146 & $3.88 \mathrm{E}-05$ & $4.94 \mathrm{E}-02$ & $1.57 \mathrm{E}-03$ & $1.92 \mathrm{E}-06$ & $3.71 \mathrm{E}-15$ & 601 & 54 & 1.93 & 1.56 & 0.01 & 0.43 & 0.842 & -0.006 & -0.022 & 1863 & 541 & a2-21 \\
\hline 474 & $5.82 \mathrm{E}-05$ & $1.32 \mathrm{E}-01$ & $3.36 \mathrm{E}-03$ & $7.68 \mathrm{E}-06$ & $3.82 \mathrm{E}-14$ & 491 & 27 & 1.57 & 1.56 & 0.00 & 0.43 & 0.839 & 0.004 & -0.017 & 2123 & 504 & a2-22 \\
\hline 141 & 3.40E- 05 & $4.14 \mathrm{E}-02$ & $1.58 \mathrm{E}-03$ & $1.41 \mathrm{E}-06$ & $2.89 \mathrm{E}-15$ & 780 & 73 & 1.51 & 1.59 & 0.00 & 0.41 & 0.838 & 0.006 & -0.039 & 2213 & 743 & a2-23 \\
\hline 236 & $7.77 \mathrm{E}-05$ & $3.56 \mathrm{E}-02$ & $1.32 \mathrm{E}-03$ & $2.77 \mathrm{E}-06$ & $1.05 \mathrm{E}-14$ & 670 & 51 & 1.53 & 1.68 & 0.00 & 0.32 & 0.850 & -0.028 & -0.021 & 1521 & 518 & a2-24 \\
\hline 390 & 4.85E-05 & $1.82 \mathrm{E}-01$ & $4.09 \mathrm{E}-03$ & $8.83 \mathrm{E}-06$ & $3.93 \mathrm{E}-14$ & 356 & 21 & 1.61 & 1.71 & 0.01 & 0.29 & 0.828 & 0.035 & -0.026 & 2079 & 261 & a2-25 \\
\hline 576 & $5.82 \mathrm{E}-05$ & $1.95 \mathrm{E}-01$ & $4.71 \mathrm{E}-03$ & 1.13E-05 & $7.51 \mathrm{E}-14$ & 407 & 21 & 1.61 & 1.79 & 0.01 & 0.20 & 0.851 & -0.032 & 0.000 & 2157 & 331 & a2-26 \\
\hline 213 & $5.82 \mathrm{E}-05$ & $5.31 \mathrm{E}-02$ & $1.52 \mathrm{E}-03$ & $3.09 \mathrm{E}-06$ & $7.83 \mathrm{E}-15$ & 546 & 42 & 1.81 & 1.50 & 0.01 & 0.50 & 0.839 & 0.004 & 0.000 & 2383 & 632 & a2-27 \\
\hline 166 & $5.82 \mathrm{E}-05$ & $4.07 \mathrm{E}-02$ & $1.02 \mathrm{E}-03$ & $2.37 \mathrm{E}-06$ & $3.52 \mathrm{E}-15$ & 555 & 46 & 1.63 & 1.58 & 0.01 & 0.41 & 0.842 & -0.006 & -0.007 & 2121 & 566 & a2-28 \\
\hline 496 & $4.85 \mathrm{E}-05$ & $2.08 \mathrm{E}-01$ & $6.17 \mathrm{E}-03$ & $1.01 \mathrm{E}-05$ & $8.95 \mathrm{E}-14$ & 394 & 22 & 1.65 & 1.57 & 0.01 & 0.42 & 0.843 & -0.009 & -0.025 & 1828 & 331 & a2-29 \\
\hline 151 & $4.37 \mathrm{E}-05$ & $4.53 \mathrm{E}-02$ & $1.16 \mathrm{E}-03$ & $1.98 \mathrm{E}-06$ & $2.57 \mathrm{E}-15$ & 602 & 52 & 1.68 & 1.52 & 0.00 & 0.47 & 0.831 & 0.027 & 0.006 & 2199 & 551 & a2-30 \\
\hline 378 & $4.85 \mathrm{E}-05$ & $1.35 \mathrm{E}-01$ & $3.42 \mathrm{E}-03$ & $6.55 \mathrm{E}-06$ & $2.75 \mathrm{E}-14$ & 461 & 28 & 1.90 & 1.76 & 0.00 & 0.24 & 0.852 & -0.036 & -0.019 & 1468 & 268 & a2-31 \\
\hline 126 & $3.88 \mathrm{E}-05$ & $5.49 \mathrm{E}-02$ & $2.02 \mathrm{E}-03$ & 2.13E-06 & $6.14 \mathrm{E}-15$ & 472 & 46 & 1.57 & 1.75 & 0.00 & 0.25 & 0.851 & -0.034 & -0.015 & 2164 & 659 & a2-32 \\
\hline 420 & $4.85 \mathrm{E}-05$ & $1.15 \mathrm{E}-01$ & $2.45 \mathrm{E}-03$ & $5.58 \mathrm{E}-06$ & $1.41 \mathrm{E}-14$ & 595 & 33 & 1.67 & 1.57 & 0.01 & 0.43 & 0.836 & 0.013 & 0.008 & 2311 & 397 & a2-33 \\
\hline 358 & $4.85 \mathrm{E}-05$ & 7.63E-02 & $1.91 \mathrm{E}-03$ & $3.70 \mathrm{E}-06$ & $8.58 \mathrm{E}-15$ & 754 & 46 & 1.67 & 1.59 & 0.01 & 0.40 & 0.841 & - & -0.002 & 1763 & 395 & a2-34 \\
\hline 193 & $3.40 \mathrm{E}-05$ & $1.23 \mathrm{E}-01$ & $2.53 \mathrm{E}-03$ & $4.18 \mathrm{E}-06$ & $7.40 \mathrm{E}-15$ & 371 & 28 & 1.66 & 1.66 & 0.00 & 0.34 & 0.842 & -0.006 & -0.009 & 2042 & 417 & a2-35 \\
\hline 137 & $3.40 \mathrm{E}-05$ & $4.75 \mathrm{E}-02$ & $1.10 \mathrm{E}-03$ & $1.62 \mathrm{E}-06$ & $1.40 \mathrm{E}-15$ & 666 & 60 & 1.50 & 1.60 & 0.01 & 0.39 & 0.835 & 0.014 & 0.003 & 2268 & 558 & a2-36 \\
\hline 306 & $3.88 \mathrm{E}-05$ & $1.33 \mathrm{E}-01$ & $3.15 \mathrm{E}-03$ & $5.16 \mathrm{E}-06$ & $1.49 \mathrm{E}-14$ & 473 & 30 & 1.60 & 1.78 & 0.00 & 0.22 & 0.848 & -0.023 & -0.016 & 1867 & 269 & a2-37 \\
\hline 86 & $3.11 \mathrm{E}-05$ & $4.56 \mathrm{E}-02$ & $9.85 \mathrm{E}-04$ & $1.42 \mathrm{E}-06$ & $9.38 \mathrm{E}-16$ & 483 & 54 & 1.54 & 1.77 & 0.01 & 0.23 & 0.847 & -0.021 & -0.006 & 2386 & 515 & a2-38 \\
\hline 338 & $4.85 \mathrm{E}-05$ & $1.45 \mathrm{E}-01$ & $2.34 \mathrm{E}-03$ & 7.03E-06 & $1.29 \mathrm{E}-14$ & 386 & 23 & 1.56 & 1.69 & 0.00 & 0.31 & 0.849 & -0.028 & -0.031 & 1470 & 213 & a2-39 \\
\hline 101 & $3.40 \mathrm{E}-05$ & $5.79 \mathrm{E}-02$ & $1.19 \mathrm{E}-03$ & $1.97 \mathrm{E}-06$ & $1.64 \mathrm{E}-15$ & 411 & 42 & 1.71 & 1.62 & 0.01 & 0.37 & 0.836 & 0.013 & -0.021 & 2304 & 469 & a2-40 \\
\hline 14353 & $2.61 \mathrm{E}-03$ & & & $2.40 \mathrm{E}-04$ & $1.20 \mathrm{E}-12$ & 512 & 18 & 1.77 & 1.63 & 0.01 & 0.36 & 0.842 & -0.004 & -0.010 & 2075 & 67 & \\
\hline
\end{tabular}

$\mathrm{N}_{s}=$ spontaneous track count; $\Omega_{i}=$ track count area; $\mathrm{P}_{i}=$ down-pit weighted ${ }^{238} \mathrm{U} /{ }^{43} \mathrm{Ca}$ ratio

$\dagger$ AFT single-grain ages are calculated using the LA-ICPMS ( $\zeta$-calibration) method with modified $\zeta=8.2727$, standard error $(\zeta)=0.1407$ and 238 U total decay constant of $1.55125 \times 10^{-10} \mathrm{yr}^{-1}$. Bottom table row (bold) displays the analysis sums, AFT central age $\pm 1 \sigma$ error, and the mean values for the summary calculations but are reported for completeness; see discussion in Issler et al., 2021.

$\star$ Average values reported for $\mathrm{F}, \mathrm{Cl}, \mathrm{OH}, \mathrm{D}$ par, and effective $\mathrm{Cl}(\mathrm{eCl})$ in bottom row, median value shown for $\mathrm{r}_{m r 0}$; Individual grain $\mathrm{D}$ par values are the mean of 4 measurements. Aliquot 2 had two EPMA probe spots, one near the AFT laser ablation pit (A) and another elsewhere on the grain (B) to assess
compositional heterogeneity. Only elemental data for spot A are reported here for aliquot 2 . Average wt \% oxide total for aliquot 2 replicates is $97.4 \pm 1.8 \%$; compositional heterogeneity
median $=98 \%(\mathrm{n}=74)$.

$\ddagger$ Individual U-Pb dates are common Pb-corrected isotopic sums. Summary U-Pb date of $2075 \pm 67 \mathrm{Ma}$ in the table is the simple weighted mean of individual dates $\left(2 \sigma, \mathrm{n}=49 / 53, \mathrm{MSWD}=1.51, \mathrm{P}\left(\chi^{2}\right)=0.013\right)$. The weighted mean ${ }^{207} \mathrm{~Pb} /{ }^{206} \mathrm{~Pb}$ date calculated in IsoplotR (Vermeesch, 2018$)$ using ${ }^{238} \mathrm{U} /{ }^{206} \mathrm{~Pb}$ and ${ }^{207} \mathrm{~Pb} /{ }^{206} \mathrm{~Pb}$ isotopic ratios is $2173 \pm 72 \mathrm{Ma}\left(2 \sigma\right.$ with overdispersion, $\left.\mathrm{n}=53 / 53, \mathrm{MSWD}=1.8, \mathrm{P}\left(\chi^{2}\right)=0.00\right)$. 
Table 2: Apatite fission-track data for sample CB99-227, Trans-Hudson Orogen.

\begin{tabular}{|c|c|c|c|c|c|c|c|c|c|c|c|c|c|c|c|c|c|}
\hline $\mathbf{N}_{s}$ & $\begin{array}{c}\operatorname{Area}\left(\Omega_{i}\right) \\
\left(\mathbf{c m}^{2}\right)\end{array}$ & ${ }^{238} \mathbf{U} /{ }^{43} \mathbf{C a}$ & $1 \sigma$ & $\mathbf{P}_{i} \Omega_{i}$ & $\sigma \mathbf{P}_{i}^{2} \Omega_{i}^{2}$ & $\begin{array}{c}\text { AFT age } \dagger \\
\text { (Ma) }\end{array}$ & $\begin{array}{c}1 \sigma \\
(\mathrm{Ma})\end{array}$ & $\begin{array}{l}\mathbf{D}_{p a r} \\
(\mu \mathrm{m})\end{array}$ & $\begin{array}{c}\mathbf{F} \star \\
(\mathrm{apfu})\end{array}$ & $\begin{array}{c}\mathrm{Cl} \star \\
(\mathrm{apfu})\end{array}$ & $\begin{array}{c}\mathrm{OH} \star \\
(\mathrm{apfu})\end{array}$ & $\begin{array}{l}\mathbf{r}_{m r 0} \\
1999\end{array}$ & $\begin{array}{c}\mathrm{eCl}(\mathrm{A}) \\
(\mathrm{apfu})\end{array}$ & $\begin{array}{c}\mathrm{eCl}(\mathrm{B}) \\
\text { (apfu) }\end{array}$ & $\begin{array}{c}\mathrm{U}-\mathbf{P b} \ddagger \\
\text { age (Ma) }\end{array}$ & $\begin{array}{c}2 \sigma \\
(\mathrm{Ma})\end{array}$ & $\begin{array}{c}\text { aliquot } \\
\text { grain }\end{array}$ \\
\hline 461 & $5.82 \mathrm{E}-05$ & $1.33 \mathrm{E}-01$ & $2.97 \mathrm{E}-03$ & $7.77 \mathrm{E}-06$ & $2.98 \mathrm{E}-14$ & 473 & 26 & 2.09 & 1.65 & 0.01 & 0.34 & 0.848 & -0.022 & - & 1526 & 208 & a1-1 \\
\hline 175 & $3.88 \mathrm{E}-05$ & $4.07 \mathrm{E}-02$ & $2.14 \mathrm{E}-03$ & $1.58 \mathrm{E}-06$ & $6.88 \mathrm{E}-15$ & 856 & 80 & 1.91 & 1.55 & 0.01 & 0.44 & 0.838 & 0.008 & - & 1471 & 319 & a1-2 \\
\hline 367 & $5.82 \mathrm{E}-05$ & $8.80 \mathrm{E}-02$ & $1.97 \mathrm{E}-03$ & $5.12 \mathrm{E}-06$ & $1.32 \mathrm{E}-14$ & 567 & 34 & 2.16 & - & - & - & - & - & - & 1581 & 221 & a1-3 \\
\hline 131 & $2.91 \mathrm{E}-05$ & $7.94 \mathrm{E}-02$ & $1.85 \mathrm{E}-03$ & $2.31 \mathrm{E}-06$ & $2.91 \mathrm{E}-15$ & 452 & 42 & 2.16 & 1.69 & 0.01 & 0.30 & 0.848 & -0.025 & - & 1559 & 152 & a1-4 \\
\hline 257 & $9.71 \mathrm{E}-05$ & $3.00 \mathrm{E}-02$ & $6.97 \mathrm{E}-04$ & $2.91 \mathrm{E}-06$ & $4.57 \mathrm{E}-15$ & 692 & 48 & 2.16 & 1.61 & 0.01 & 0.38 & 0.843 & -0.009 & - & 1621 & 293 & a1-5 \\
\hline 241 & $5.82 \mathrm{E}-05$ & $6.46 \mathrm{E}-02$ & $1.74 \mathrm{E}-03$ & 3.76E-06 & 1.02E-14 & 509 & 37 & 2.20 & 1.53 & 0.01 & 0.46 & 0.841 & -0.001 & - & 1572 & 213 & a1-6 \\
\hline 72 & $3.88 \mathrm{E}-05$ & $2.42 \mathrm{E}-02$ & $5.89 \mathrm{E}-04$ & $9.38 \mathrm{E}-07$ & 5.23E-16 & 606 & 74 & 2.12 & 1.53 & 0.01 & 0.46 & 0.837 & 0.011 & - & 1605 & 301 & a1-7 \\
\hline 211 & $4.85 \mathrm{E}-05$ & $3.83 \mathrm{E}-02$ & $8.69 \mathrm{E}-04$ & $1.86 \mathrm{E}-06$ & $1.78 \mathrm{E}-15$ & 878 & 65 & 1.59 & 1.74 & 0.01 & 0.25 & 0.851 & -0.033 & - & 1541 & 219 & a1-8 \\
\hline 103 & $4.85 \mathrm{E}-05$ & $2.99 \mathrm{E}-02$ & $7.08 \mathrm{E}-04$ & $1.45 \mathrm{E}-06$ & $1.18 \mathrm{E}-15$ & 562 & 58 & 2.10 & 1.50 & 0.01 & 0.49 & 0.835 & 0.016 & - & 1582 & 323 & a1-9 \\
\hline 197 & $5.82 \mathrm{E}-05$ & $3.77 \mathrm{E}-02$ & $9.32 \mathrm{E}-04$ & $2.20 \mathrm{E}-06$ & $2.95 \mathrm{E}-15$ & 703 & 54 & 2.25 & 1.67 & 0.02 & 0.31 & 0.838 & 0.007 & - & 1528 & 281 & a1-10 \\
\hline 71 & $3.88 \mathrm{E}-05$ & $1.98 \mathrm{E}-02$ & 7.41E-04 & 7.70E-07 & 8.27E-16 & 721 & 91 & 1.80 & 1.59 & 0.01 & 0.39 & 0.837 & 0.011 & - & 1433 & 566 & a1-11 \\
\hline 438 & $5.82 \mathrm{E}-05$ & $9.98 \mathrm{E}-02$ & $3.01 \mathrm{E}-03$ & $5.81 \mathrm{E}-06$ & $3.08 \mathrm{E}-14$ & 595 & 35 & 1.89 & 1.59 & 0.01 & 0.39 & 0.833 & 0.022 & - & 1516 & 261 & a1-12 \\
\hline 153 & $4.37 \mathrm{E}-05$ & $5.64 \mathrm{E}-02$ & $1.22 \mathrm{E}-03$ & $2.46 \mathrm{E}-06$ & $2.83 \mathrm{E}-15$ & 494 & 42 & 2.22 & 1.64 & 0.01 & 0.35 & 0.846 & -0.019 & - & 1596 & 219 & a1-13 \\
\hline 334 & $6.21 \mathrm{E}-05$ & $5.62 \mathrm{E}-02$ & $1.37 \mathrm{E}-03$ & $3.49 \mathrm{E}-06$ & $7.22 \mathrm{E}-15$ & 746 & 46 & 2.07 & 1.73 & 0.01 & 0.26 & 0.851 & -0.034 & - & 1541 & 234 & a1-14 \\
\hline 343 & 7.77E-05 & 3.51E-02 & $1.24 \mathrm{E}-03$ & $2.73 \mathrm{E}-06$ & $9.29 \mathrm{E}-15$ & 965 & 64 & 2.22 & 1.64 & 0.01 & 0.35 & 0.847 & -0.021 & - & 1485 & 374 & a1-15 \\
\hline 615 & $5.82 \mathrm{E}-05$ & $2.29 \mathrm{E}-01$ & $4.70 \mathrm{E}-03$ & $1.34 \mathrm{E}-05$ & 7.51E-14 & 370 & 18 & 1.64 & 1.53 & 0.01 & 0.47 & 0.836 & 0.013 & 0.026 & 1722 & 285 & a2-1 \\
\hline 714 & $5.82 \mathrm{E}-05$ & $2.18 \mathrm{E}-01$ & $4.38 \mathrm{E}-03$ & $1.27 \mathrm{E}-05$ & 6.51E-14 & 449 & 21 & 1.70 & 1.43 & 0.01 & 0.56 & 0.834 & 0.018 & 0.025 & 1661 & 219 & a2-2 \\
\hline 103 & $3.98 \mathrm{E}-05$ & $3.87 \mathrm{E}-02$ & $6.06 \mathrm{E}-03$ & $1.54 \mathrm{E}-06$ & $5.82 \mathrm{E}-14$ & 530 & 99 & 2.16 & 1.60 & 0.01 & 0.39 & 0.837 & 0.010 & - & - & - & a2-3 \\
\hline 218 & $9.71 \mathrm{E}-05$ & $8.79 \mathrm{E}-02$ & $3.06 \mathrm{E}-03$ & $8.53 \mathrm{E}-06$ & $8.80 \mathrm{E}-14$ & 208 & 16 & 1.74 & 1.45 & 0.01 & 0.54 & 0.837 & 0.010 & 0.036 & - & - & a2-4 \\
\hline 114 & $4.37 \mathrm{E}-05$ & $4.08 \mathrm{E}-02$ & $1.90 \mathrm{E}-03$ & $1.78 \mathrm{E}-06$ & $6.91 \mathrm{E}-15$ & 509 & 54 & 1.43 & 1.59 & 0.01 & 0.41 & 0.835 & 0.015 & -0.023 & - & - & $a 2-5$ \\
\hline 118 & $9.71 \mathrm{E}-05$ & $2.15 \mathrm{E}-02$ & $1.73 \mathrm{E}-03$ & $2.09 \mathrm{E}-06$ & $2.82 \mathrm{E}-14$ & 452 & 56 & 1.54 & 1.51 & 0.01 & 0.48 & 0.839 & 0.003 & 0.013 & - & - & a2-6 \\
\hline 138 & $5.82 \mathrm{E}-05$ & $4.77 \mathrm{E}-02$ & $9.40 \mathrm{E}-04$ & $2.78 \mathrm{E}-06$ & $3.00 \mathrm{E}-15$ & 399 & 35 & 1.63 & 1.60 & 0.01 & 0.40 & 0.835 & 0.017 & -0.021 & 1626 & 478 & a2-7 \\
\hline 80 & $4.37 \mathrm{E}-05$ & $3.91 \mathrm{E}-02$ & $8.71 \mathrm{E}-03$ & $1.71 \mathrm{E}-06$ & $1.45 \mathrm{E}-13$ & 376 & 94 & 1.41 & - & - & - & - & - & - & - & - & a2-8 \\
\hline 145 & $4.85 \mathrm{E}-05$ & $2.88 \mathrm{E}-02$ & $7.38 \mathrm{E}-04$ & $1.40 \mathrm{E}-06$ & $1.28 \mathrm{E}-15$ & 806 & 71 & 1.49 & 1.55 & 0.00 & 0.45 & 0.842 & -0.006 & 0.001 & 1631 & 607 & a2-9 \\
\hline 384 & $2.91 \mathrm{E}-05$ & $3.37 \mathrm{E}-01$ & $6.10 \mathrm{E}-03$ & $9.81 \mathrm{E}-06$ & $3.15 \mathrm{E}-14$ & 316 & 18 & 1.68 & 1.57 & 0.01 & 0.42 & 0.837 & 0.009 & 0.025 & 1593 & 195 & a2-10 \\
\hline 472 & $4.85 \mathrm{E}-05$ & $1.95 \mathrm{E}-01$ & $3.91 \mathrm{E}-03$ & $9.47 \mathrm{E}-06$ & $3.61 \mathrm{E}-14$ & 400 & 21 & 1.79 & 1.45 & 0.01 & 0.55 & 0.832 & 0.024 & 0.016 & 1635 & 232 & a2-11 \\
\hline 294 & $6.79 \mathrm{E}-05$ & $5.78 \mathrm{E}-02$ & 1.41E-03 & $3.92 \mathrm{E}-06$ & $9.20 \mathrm{E}-15$ & 592 & 39 & 2.16 & 1.52 & 0.02 & 0.46 & 0.833 & 0.020 & 0.028 & 1624 & 426 & a2-12 \\
\hline 440 & $4.85 \mathrm{E}-05$ & $1.67 \mathrm{E}-01$ & $3.35 \mathrm{E}-03$ & 8.11E-06 & $2.65 \mathrm{E}-14$ & 434 & 24 & 1.89 & 1.52 & 0.02 & 0.46 & 0.833 & 0.022 & 0.017 & 1615 & 289 & a2-13 \\
\hline 128 & $4.85 \mathrm{E}-05$ & $4.35 \mathrm{E}-02$ & $1.25 \mathrm{E}-03$ & $2.11 \mathrm{E}-06$ & $3.67 \mathrm{E}-15$ & 483 & 46 & 1.89 & 1.69 & 0.01 & 0.30 & 0.849 & -0.026 & 0.010 & 1560 & 421 & a2-14 \\
\hline 324 & $9.71 \mathrm{E}-05$ & $5.34 \mathrm{E}-02$ & $1.42 \mathrm{E}-03$ & $5.19 \mathrm{E}-06$ & $1.89 \mathrm{E}-14$ & 497 & 32 & 1.87 & 1.68 & 0.01 & 0.31 & 0.848 & -0.022 & 0.017 & 1547 & 661 & a2-15 \\
\hline 119 & $4.85 \mathrm{E}-05$ & $3.60 \mathrm{E}-02$ & $1.23 \mathrm{E}-03$ & 1.75E-06 & $3.57 \mathrm{E}-15$ & 541 & 54 & 1.64 & - & - & - & - & - & - & 1548 & 535 & a2-16 \\
\hline 404 & $4.85 \mathrm{E}-05$ & $1.25 \mathrm{E}-01$ & $3.01 \mathrm{E}-03$ & $6.05 \mathrm{E}-06$ & $2.14 \mathrm{E}-14$ & 530 & 31 & 1.71 & 1.49 & 0.01 & 0.50 & 0.841 & -0.001 & -0.022 & 1473 & 324 & a2-17 \\
\hline 195 & $5.82 \mathrm{E}-05$ & $6.32 \mathrm{E}-02$ & $1.57 \mathrm{E}-03$ & $3.68 \mathrm{E}-06$ & $8.35 \mathrm{E}-15$ & 424 & 33 & 1.71 & 1.61 & 0.01 & 0.38 & 0.837 & 0.011 & -0.003 & 1641 & 418 & a2-18 \\
\hline 234 & $4.85 \mathrm{E}-05$ & $6.93 \mathrm{E}-02$ & $2.43 \mathrm{E}-03$ & $3.37 \mathrm{E}-06$ & $1.39 \mathrm{E}-14$ & 551 & 42 & 1.72 & 1.51 & 0.02 & 0.48 & 0.831 & 0.028 & 0.018 & - & - & a2-19 \\
\hline 242 & $5.82 \mathrm{E}-05$ & 7.26E-02 & $2.72 \mathrm{E}-03$ & $4.23 \mathrm{E}-06$ & $2.50 \mathrm{E}-14$ & 457 & 35 & 1.65 & 1.52 & 0.01 & 0.46 & 0.836 & 0.012 & -0.013 & - & - & a2-20 \\
\hline 203 & $2.91 \mathrm{E}-05$ & $1.50 \mathrm{E}-01$ & $7.94 \mathrm{E}-03$ & $4.37 \mathrm{E}-06$ & $5.35 \mathrm{E}-14$ & 373 & 33 & 1.77 & 1.52 & 0.01 & 0.47 & 0.834 & 0.018 & 0.008 & - & - & a2-21 \\
\hline 140 & $3.88 \mathrm{E}-05$ & $5.66 \mathrm{E}-02$ & $2.68 \mathrm{E}-03$ & $2.20 \mathrm{E}-06$ & $1.08 \mathrm{E}-14$ & 507 & 50 & 1.60 & 1.57 & 0.01 & 0.43 & 0.837 & 0.011 & 0.006 & - & - & a2-22 \\
\hline 555 & $5.82 \mathrm{E}-05$ & $1.55 \mathrm{E}-01$ & $4.73 \mathrm{E}-03$ & $9.05 \mathrm{E}-06$ & $7.59 \mathrm{E}-14$ & 488 & 27 & 2.03 & 1.58 & 0.01 & 0.42 & 0.845 & -0.016 & 0.003 & - & - & a2-23 \\
\hline 129 & $4.85 \mathrm{E}-05$ & $4.29 \mathrm{E}-02$ & $1.45 \mathrm{E}-03$ & $2.08 \mathrm{E}-06$ & $4.96 \mathrm{E}-15$ & 493 & 47 & 1.56 & 1.60 & 0.01 & 0.39 & 0.839 & 0.005 & -0.001 & - & - & a2-24 \\
\hline 84 & $4.85 \mathrm{E}-05$ & $1.98 \mathrm{E}-02$ & $1.35 \mathrm{E}-03$ & $9.59 \mathrm{E}-07$ & $4.30 \mathrm{E}-15$ & 687 & 89 & 1.72 & 1.57 & 0.01 & 0.42 & 0.838 & 0.008 & 0.045 & - & - & a2-25 \\
\hline 300 & $4.85 \mathrm{E}-05$ & $1.70 \mathrm{E}-01$ & $3.69 \mathrm{E}-03$ & $8.23 \mathrm{E}-06$ & $3.21 \mathrm{E}-14$ & 295 & 19 & 1.77 & 1.56 & 0.01 & 0.43 & 0.843 & -0.009 & 0.009 & - & - & a2-26 \\
\hline 316 & $4.85 \mathrm{E}-05$ & $9.24 \mathrm{E}-02$ & $2.09 \mathrm{E}-03$ & 4.49E- 06 & 1.03E-14 & 558 & 35 & 1.73 & 1.46 & 0.01 & 0.53 & 0.839 & 0.004 & -0.001 & 1637 & 292 & a2-27 \\
\hline 222 & $5.82 \mathrm{E}-05$ & $1.02 \mathrm{E}-01$ & $2.14 \mathrm{E}-03$ & $5.95 \mathrm{E}-06$ & $1.56 \mathrm{E}-14$ & 301 & 22 & 1.47 & 1.72 & 0.00 & 0.28 & 0.840 & 0.000 & -0.029 & - & - & a2-28 \\
\hline 238 & $2.91 \mathrm{E}-05$ & $2.18 \mathrm{E}-01$ & $4.37 \mathrm{E}-03$ & $6.34 \mathrm{E}-06$ & $1.62 \mathrm{E}-14$ & 303 & 21 & 2.11 & 1.58 & 0.01 & 0.42 & 0.842 & -0.004 & 0.038 & 1665 & 221 & a2-29 \\
\hline 63 & $3.88 \mathrm{E}-05$ & $3.33 \mathrm{E}-02$ & $1.76 \mathrm{E}-03$ & 1.29E-06 & 4. $69 \mathrm{E}-15$ & 391 & 54 & 1.43 & 1.71 & 0.01 & 0.28 & 0.843 & -0.009 & -0.041 & - & - & a2-30 \\
\hline 195 & $4.85 \mathrm{E}-05$ & 8.53E-02 & $2.19 \mathrm{E}-03$ & $4.14 \mathrm{E}-06$ & $1.13 \mathrm{E}-14$ & 378 & 29 & 2.17 & 1.47 & 0.01 & 0.52 & 0.835 & 0.015 & -0.013 & 1736 & 430 & a2-31 \\
\hline 248 & $4.85 \mathrm{E}-05$ & $7.39 \mathrm{E}-02$ & $1.99 \mathrm{E}-03$ & $3.59 \mathrm{E}-06$ & $9.34 \mathrm{E}-15$ & 548 & 39 & 1.51 & 1.47 & 0.01 & 0.52 & 0.836 & 0.011 & 0.001 & 1546 & 396 & a2-32 \\
\hline 290 & $5.82 \mathrm{E}-05$ & $1.22 \mathrm{E}-01$ & $3.49 \mathrm{E}-03$ & 7.09E- -06 & $4.14 \mathrm{E}-14$ & 330 & 22 & 1.72 & 1.62 & 0.02 & 0.36 & 0.840 & -0.001 & 0.007 & 1504 & 250 & a2-33 \\
\hline 98 & $2.91 \mathrm{E}-05$ & 6.77E-02 & $2.12 \mathrm{E}-03$ & $1.97 \mathrm{E}-06$ & $3.80 \mathrm{E}-15$ & 399 & 43 & 1.66 & 1.95 & 0.01 & 0.04 & 0.856 & -0.048 & 0.030 & 1614 & 279 & a2-34 \\
\hline 328 & $3.88 \mathrm{E}-05$ & $2.15 \mathrm{E}-01$ & $5.78 \mathrm{E}-03$ & $8.34 \mathrm{E}-06$ & $5.04 \mathrm{E}-14$ & 317 & 20 & 1.92 & 1.51 & 0.01 & 0.48 & 0.839 & 0.003 & -0.001 & 1753 & 304 & a2-35 \\
\hline 12444 & $2.63 \mathrm{E}-03$ & & & $2.19 \mathrm{E}-04$ & $1.14 \mathrm{E}-12$ & 486 & 22 & 1.83 & 1.58 & 0.01 & 0.41 & 0.838 & 0.001 & 0.007 & 1585 & 46 & \\
\hline
\end{tabular}

$\mathrm{N}_{s}=$ spontaneous track count; $\Omega_{i}=$ track count area; $\mathrm{P}_{i}=$ down-pit weighted ${ }^{238} \mathrm{U} /{ }^{43} \mathrm{Ca}$ ratio

$\dagger$ AFT single-grain ages are calculated using the LA-ICPMS ( $\zeta$-calibration) method with modified $\zeta=8.2727$, standard error $(\zeta)=0.1407$ and $238 \mathrm{U}$ total decay constant of $1.55125 \times 10^{-10} \mathrm{yr}^{-1}$. Bottom table row (bold) displays the analysis sums, AFT central age $\pm 1 \sigma$ error, and the mean values for the tabulated elements/kinetic parameters.

*Average values reported for $\mathrm{F}, \mathrm{Cl}, \mathrm{OH}, \mathrm{D}_{\text {par }}$, and effective $\mathrm{Cl}(\mathrm{eCl})$ in bottom row, median value shown for $\mathrm{r}_{m}$ ro ; Individual grain $\mathrm{D}_{\text {par }}$ values are the mean of 4 measurements. Aliquot 2 had two EPMA probe spots, one near the AFT laser ablation pit and another elsewhere on the grain to assess compositional hetero-
geneity. Only elemental data for spot A are reported here for aliquot 2 . Average wt \% oxide total for aliquot 2 replicates is $99.6 \pm 1.2 \% ;$ median $=99.7 \%$ ( $\mathrm{n}=65$ ).

$\ddagger$ Individual U-Pb dates are common Pb-corrected isotopic sums. Summary U-Pb date of $1585 \pm 46$ Ma in the table is the simple weighted mean of individual dates $\left(2 \sigma, \mathrm{n}=35 / 35, \mathrm{MSWD}=0.22, \mathrm{P}\left(\chi^{2}\right)=1\right)$. The weighted mean ${ }^{207} \mathrm{~Pb} /{ }^{206} \mathrm{~Pb}$ date calculated in IsoplotR (Vermeesch, 2018$)$ using ${ }^{238} \mathrm{U} /{ }^{206} \mathrm{~Pb}$ and ${ }^{207} \mathrm{~Pb} /{ }^{206} \mathrm{~Pb}$ isotopic ratios is $1603 \pm 72 \mathrm{Ma}\left(2 \sigma, \mathrm{n}=35 / 35, \mathrm{MSWD}=0.13, \mathrm{P}\left(\chi^{2}\right)=1\right)$. 
probability. The 'unconstrained' model does not include $t-T$ constraints. The geologic information being evaluated includes two distinct times in the past that we can reasonably assume basement was at near-surface conditions $\left(15 \pm 15^{\circ} \mathrm{C}\right)$ based on the regional geologic information discussed in Section 4.2. This information was subsequently added to the model as constraint boxes, namely at: $(i) 450 \pm 10 \mathrm{Ma}$ and $(i i) 175 \pm 25 \mathrm{Ma}^{2}$.

We refrain here from showing the individual maximum likelihood, maximum posterior, maximum mode, or expected model paths (Gallagher, 2012), so as not to draw undue attention to a single $t-T$ path since they are single models or a representative summary for a broader range of solutions (i.e., mode or expected model). Those models can be found in the SI or refer to the data repository for QTQt output (McDannell, 2022). We focus on the entire stationary distribution of paths, particularly the 'unconstrained' model without $t-T$ constraint boxes shown in Figure $5 \mathrm{~A}$ and $\mathrm{D}$. These examples reflect the ability of the AFTSS data to solely resolve both the thermal history and the necessary minimum level of complexity to adequately explain the data. Note that this does not mean that the true thermal history may not be more complex. Rather, any additional complexity (that does not compromise fitting the data) is not actually required by the data and so needs to be justified independently. The distributions for AFT age and mean track length for the accepted (post burn-in) models are essentially the same for every model for each sample (SI, Fig. S2). The fits to the observed track length distributions are also shown in the SI (Fig. S3). We note that the AFT age is reproduced at the margin of acceptability at the $-2 \sigma$ level for all examples, whereas the mean track length is well determined. This remained true throughout model trials with a larger general $t-T$ prior and the addition of constraint boxes at high temperatures. We conclude that the high number of track length measurements dominate the (log) likelihood values and thus exert more influence on the inversion results.

\section{Discussion}

\subsection{Burial and erosion history interpretations}

For both samples, nearly identical Phanerozoic thermal histories are recovered without enforcing geologic constraints - yet both models independently corroborate the known cratonic geology by requiring two reheating events. Given the imposition of simple models, the time-temperature paths also indirectly need periods at low temperatures in the mid Mesozoic to produce a heating event. Thus, the thermal histories suggest similar, albeit poorly resolved surface conditions in the late Precambrian to early Paleozoic (Fig. 5). The low temperatures are required to form a population of tracks that are then shortened by reheating to produce the observed lengths - without this, a certain component of lengths cannot be generated that are needed to fit

\footnotetext{
${ }^{2}$ Placement of a Miocene surface constraint at $14 \pm 9 \mathrm{Ma}$ did not significantly change the results when compared to the 'unconstrained' or 'Ordovician/Jurassic box' models, and was therefore excluded for simplicity. The AFT data independently allow cooling to near-surface temperatures by Miocene time.
} 

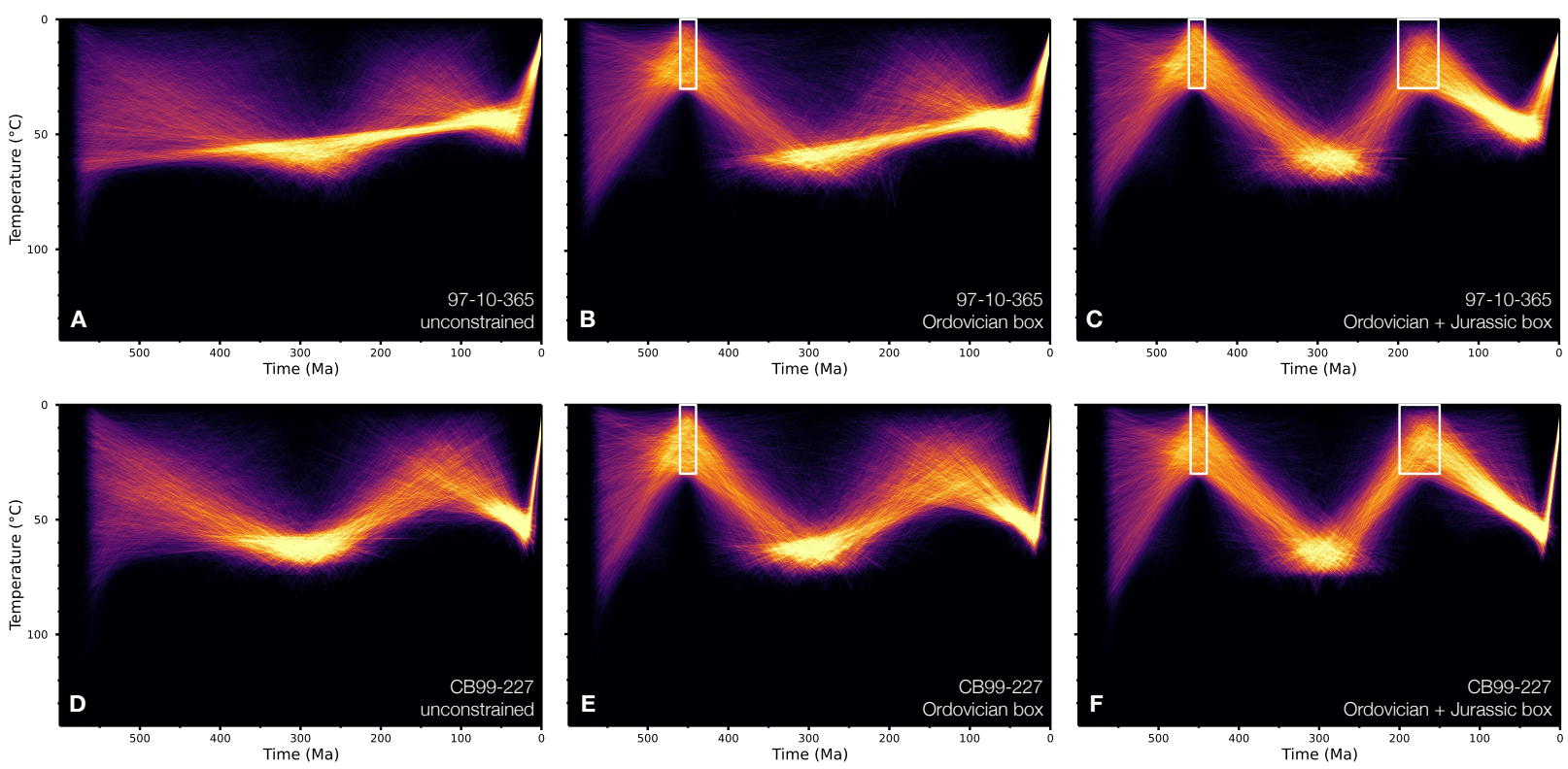

Figure 5: QTQt time-temperature simulations shown as path density heat maps resolved to a pixel size of 1 My and $1{ }^{\circ} \mathrm{C}$. Relative probability is proportional to path density, where brighter colors (or higher saturation) indicate more thermal histories pass through that region. More complex $t-T$ paths were rejected in QTQt for equivalent likelihood. (A-C) models results for sample 97-10-365. (D-F) model results for sample CB99-227. Geologic constraint boxes (white) represent Ordovician and Jurassic unconformities discussed in Section 4.2. A notable result is that the general features of the two-peak thermal history are visible in the unconstrained models. The high-quality track length data resolved the heating events and the $t-T$ solutions independently support the regional geologic information. The 'unconstrained' model in panel A clearly illustrates the penalization of more complex histories due to more simple, 'linear' paths being accepted or retained preferentially between the two thermal peaks. All QTQt models are available in McDannell (2022).

the observations. It may be that time or duration at higher temperatures become increasingly important over long timescales, which we can similarly observe in Figure 3 where maximum temperatures are slightly lower than the true peak and a subset of paths remain nearly isothermal, therefore producing similar amounts of annealing as the true history with high maximum temperatures for a geologically instantaneous duration. The AFTSS models best resolve a broad thermal peak between approximately latest Devonian to Triassic (c. 360 to $240 \mathrm{Ma}$ ) for both samples that is consistent for all simulations (Fig. 5; albeit more defined in panels $\mathrm{C}$ and $\mathrm{F}$ ). The timing of maximum temperature is poorly constrained due to the low degree of thermal annealing within the PAZ for these apatites and also partially reflects the trade-off between $t-T$ path inflections (i.e., uncertainty on the times at hotter vs. cooler temperatures; Fig. 5A-B, D-E) and the allowable heating-cooling rates imposed on the solutions. Step-wise addition of the Ordovician and Jurassic constraint boxes (Fig. 5B-C and E-F) refine the overall history results and the requirement of two heating events by the AFTSS data suggest maximum (burial) heating to $\sim 70-75^{\circ} \mathrm{C}$ occurred at $c$. $300 \mathrm{Ma}$. The timing of maximum temperature at $300 \mathrm{Ma}$ is provocative because it lends support for the deposition of Pennsylvanian strata on the Hudson platform, which was controversially posed by Tillement et al. (1976). The Michigan and Williston basins also contain a few hundred meters of Pennsylvanian and Jurassic strata (e.g., Burrus et al., 1996; Burgess, 2019), perhaps suggesting a regionally common history for interior North 
America. The final cooling event in the model takes place in the Oligocene-Miocene. The White River Group $(<38 \mathrm{Ma})$ provides geological support for this as it records the last burial event during the Paleogene in the Williston Basin, which was followed by Miocene erosion (Burrus et al., 1996). These model thermal histories are significant because they further establish that burial extended across the currently exposed basement of the Canadian Shield, that the Hudson Bay sedimentary succession is an erosional remnant (Pinet et al., 2013; McDannell et al., 2021), and the Hudson Bay and Williston basins were probably intermittently connected.

In summary, model results indicate $\sim 2-3 \mathrm{~km}$ of Paleozoic burial followed by erosion until the Jurassic (assuming a $10^{\circ} \mathrm{C}$ surface temperature and $20-30^{\circ} \mathrm{C} / \mathrm{km}$ paleo-geothermal gradient). The Mesozoic-Cenozoic history is characterized by inferred $\sim 1.5-2.5 \mathrm{~km}$ of burial during the Cretaceous to Oligocene-Miocene, and subsequent erosion (with climatic cooling?) until present day. While speculative, the timing of late cooling approximately aligns with climate change and the growth of the Antarctic ice sheet, including ephemeral northern hemisphere Oligocene-Miocene continental glaciation (Tripati and Darby, 2018, and refs. therein).

\subsection{Modeling fission-track length distributions}

The inferred complexity of a thermal history is related to the number of track lengths (Fig. 3). Our simulations clearly show that our AFTSS data have enough lengths to independently require two thermal events (i.e., without requiring $t-T$ boxes) during the Phanerozoic for the exposed Precambrian basement of the central Canadian Shield - but adding the constraints improves the resolution on the timing of maximum temperatures. However, it seems clear that 100 measured tracks for a single kinetic AFT population are not enough to resolve complicated deep-time thermal histories without applying interpretation-based constraints (e.g., McDannell et al., 2021; McDannell and Issler, 2021). To further explore this with the real data, we took the entire length dataset for each AFT example and randomly downsampled it using a simple Monte Carlo method, retaining $\sim 10 \%, \sim 20 \%$, and $\sim 50 \%$ of the original length distributions, while maintaining a stable mean length within uncertainty (Fig. 6). This was done to determine how well we resolve the two thermal peaks in the full model $t-T$ history from Figure $5 \mathrm{~A}$ and $\mathrm{D}$ with a reduced number of length measurements. This essentially simulates what a real AFT analysis would be like if fewer measurements were collected. Each resampled distribution was modelled in QTQt, while keeping the AFT age information fixed to assess how resampling of the total number of track lengths affected the model resolution. The results (Fig. 7) indicate that there is an inadequate amount of track length data in a typical AFT analysis (100 lengths) to fully or independently resolve a complex cratonic thermal history involving minor annealing in response to temperatures equivalent to the lower temperature end of the PAZ. A notable feature of the 97-10-365 models is that the timing of the last cooling event is poorly resolved (Fig. 7A) and is shifted 'younger' but becomes better defined with the progressive inclusion of more track length data (Fig. 7B-C). The track 

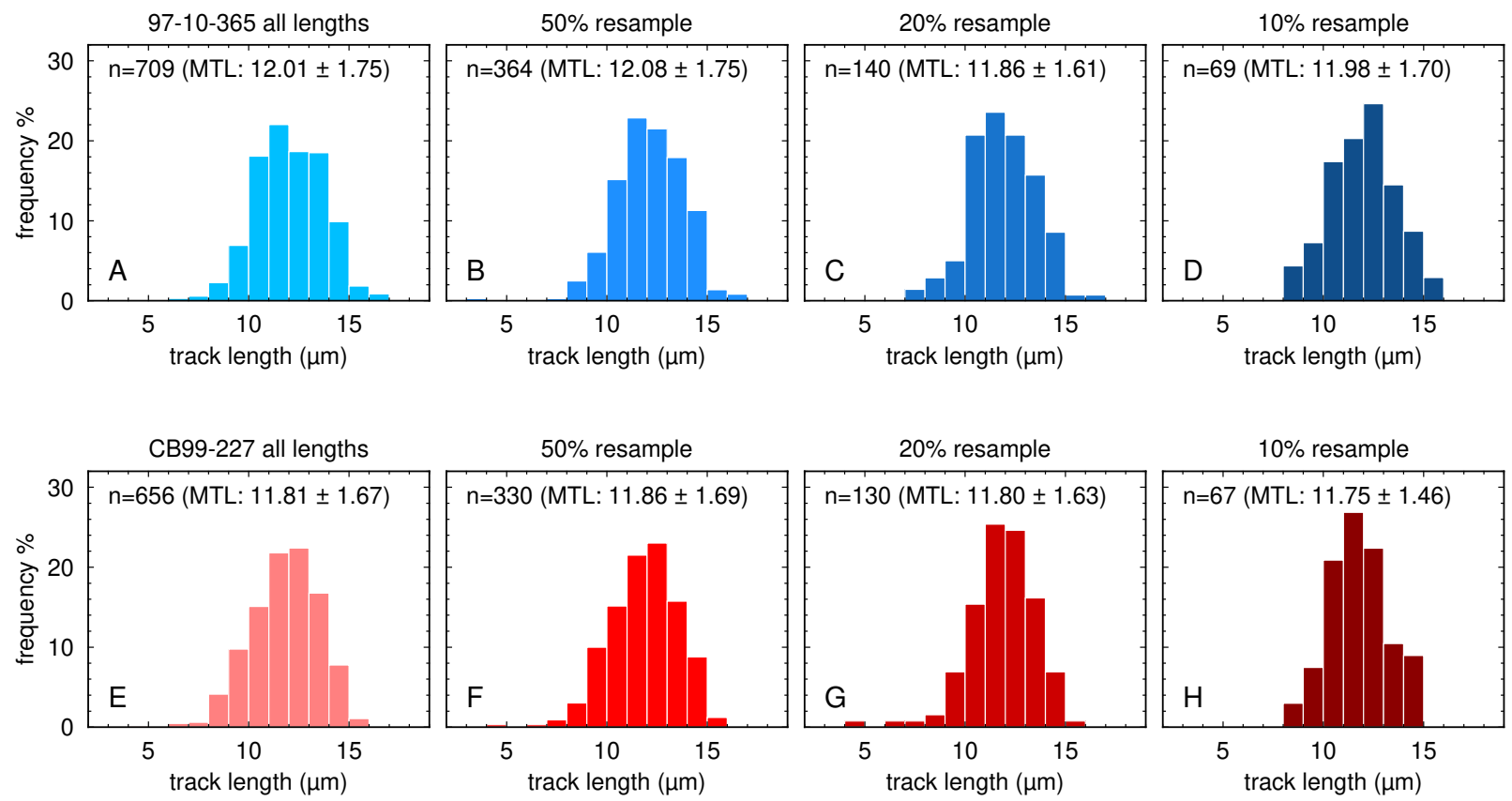

Figure 6: Conventional (i.e., unprojected) track length distributions for the AFTSS as histograms with $1 \mu \mathrm{m}$ bins. Track lengths are displayed as they were originally measured but were modelled using c-axis angles (see below). (A) all 709 track lengths combined from both sample aliquots of 97-10-365 with a conventional mean track length of $12.01 \pm 1.75 \mu \mathrm{m}$ and c-axis projected mean length of 13.63 $\pm 1.02 \mu \mathrm{m}$. (B) random $50 \%$ downsampling or resampling of the total lengths in panel A. (C) random $20 \%$ resampling of the total lengths in panel A. (D) random $10 \%$ resampling of the total lengths in panel A. Sample CB99-227 (E-H) is the same as panels A-D with a conventional mean track length of $11.81 \pm 1.67 \mu \mathrm{m}$ and c-axis projected mean length of $13.53 \pm 0.94 \mu \mathrm{m}$. All distributions in panels $\mathrm{B}-\mathrm{D}$ and $\mathrm{F}-\mathrm{H}$ are similar in form to the ones in A and E, respectively. MTL = mean track length.

resampling exercise (Fig. 6) implies that more short/intermediate lengths and overall broadening of the track distribution are required (absent in the low $n$ models) to better resolve the timing of recent cooling. This pattern broadly aligns with the results in Figure 2. The timing of cooling to surface conditions agrees with the occurrence of Miocene strata in the INCO borehole (Galloway et al., 2012; Fig. 4). In this particular instance, we have geologic information to empirically validate our model, whereas in more frontier regions where less Phanerozoic strata are known or preserved, a $t-T$ model such as this may be more difficult to justify or be considered an artifact. To that end, AFTSS data may be extremely valuable for inferring and resolving the timing of unrecognized or poorly recorded geologic events on cratons.

The results of our modeling emphasize that amount of track length data is possibly too low in many cratonic $t-T$ modeling applications and that inadequate characterization of length distributions may affect our ability to recover thermal history information. While this is not conceptually novel — what constitutes a robust track length dataset and if those data can independently support geologic observations has gone mostly unrecognized. While the mean track length is often a useful summary statistic, it is the width and shape of the track length distribution that are critical for modeling (Crowley, 1985; Gleadow et al., 1986). The main body of the distribution needs to be well defined with many tracks, but the tails of the true distribution also need to be well represented. Namely, any shorter lengths that provide key temperature information must 

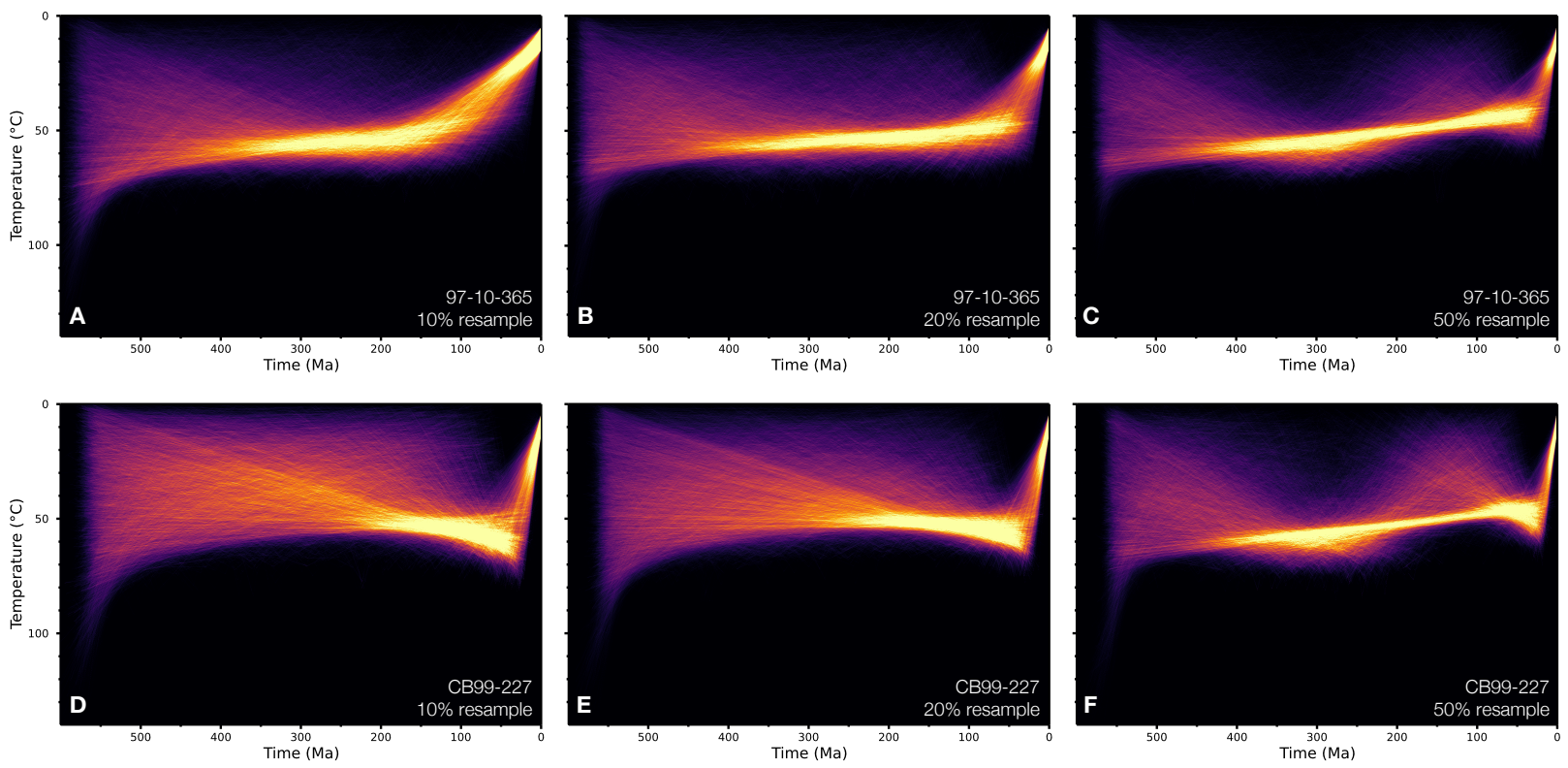

Figure 7: QTQt time-temperature simulations shown as path density heat maps. All other figure attributes and model run conditions are the same as Figure 5. (A-C) models results for 69, 140, and 364 randomly resampled track lengths for sample 97-10-365. (D-F) model results for 67, 130, and 330 randomly resampled track lengths for sample CB99-227. The two-peak history is not resolved until > 250-300 tracks are utilized during modeling. Models for 30\% and 40\% track resampling not shown for simplicity.

be included, which will typically require more measurements because they have a lower probability both of being observed and measured accurately (Laslett et al., 1982). C-axis angle projection of track lengths also plays a role in improving resolution by reducing length dispersion due to track orientation (Donelick et al., 1999), yielding a better defined length distribution (Ketcham et al., 2018; Ketcham, 2019) - thereby taking advantage of the extra information contained in the annealing dependence on track orientation. If the distribution shape is well characterized then the thermal model can deconvolve the mixed length components generated by the different heating-cooling cycles.

In detail, many different thermal histories can satisfy a given track length distribution. However, even if the distribution looks similar between an example with many tracks and fewer tracks, the possibility to resolve multiple heating-cooling events in a history is reduced in the latter case. A good example of this is apparent in the downsampling results shown in Figure 6. Here the increased number of tracks tends to broaden the overall distribution, implying (or requiring) greater history complexity - which is then verified in the Figure 7 inversion results. The same limitations can apply to different forms of thermal histories as reflected for the example shown in Figure 1. The real slow-cooling history may be misinterpreted as rapid and/or recent cooling if the skewed distribution (Fig. 1C) were undersampled such that shorter lengths were not measured. The same generally applies to the broad distribution (Fig. 1D) if there are not enough intermediate $(\sim 12-13$ $\mu \mathrm{m})$ and/or long $(\sim 15-16 \mu \mathrm{m})$ c-axis projected lengths collated to distinguish between a narrow or wide unimodal track population. In addition, the synthetic AFT inversions (Fig. 3) suggest to us that exploratory 
forward modeling potentially offers a means to practically estimate the number of track lengths required for a robust AFT analysis if a 'schematic' burial history can be surmised from the regional geology or other data. However, it should be noted that if old cratonic AFT samples are thermally reset $\left(>120^{\circ} \mathrm{C}\right.$; depending upon apatite composition) at any time during the Phanerozoic - then the additional $t-T$ information normally provided by an AFTSS analysis will diminish in relation to the timing of the resetting event (i.e., a thermal pulse late in the history will tend to erase or at least reduce the information provided by additional lengths). The examples and model results presented here demonstrate that a minimum of $\sim 250-300$ confined length measurements are required for robust thermal history recovery for single-age population samples in cratonic regions where rocks experienced modest thermal annealing over the past 500-600 million years.

\section{Conclusions}

Studies of cratons have shown that they are typically characterized by long duration and episodic thermal histories involving low to moderate degrees of thermal annealing from sedimentary burial. Apatite fission-track dating has traditionally been a preferred method for constraining aspects of these complex burial and erosion events. However, due to the absence of physical geologic constraints, detailed thermal history reconstruction is often difficult. This issue leads to a thermal history modeling approach that incorporates interpretive assumptions about the geologic history that may be invalid or at least difficult to validate independently. New apatite fission-track data were presented from the central Canadian Shield that included many more confined track-length measurements than a typical fission-track analysis. Inversions of these data yield results that are consistent with the regional shield geology without requiring the imposition of $t-T$ 'constraint boxes'. Subsequently, consideration of known geologic constraints with either forward or inverse modeling approaches allows an assessment of the impact of constraints relative to the unconstrained thermal histories. While the appropriate number of tracks lengths to collect is a function of the thermal history, our results demonstrate that the conventional approach of measuring around 100 track lengths may be inadequate for long duration (500-1000 My) thermal history scenarios involving a higher level of history complexity and/or episodic minor annealing. Ultimately, each problem is unique and analyses should be tailored to optimize the amount of information available for modeling since a standardized approach may not yield sufficient data to clearly resolve significant thermal events. We suggest that 250-300 confined track lengths (with c-axis angles) may be considered an effective minimum - suitable for thermal history inversion in cratonic settings for rocks that contain a single kinetic population and have experienced low-to-moderate thermal annealing. This simple change in analytical protocol may improve thermal history recovery and lend more credence to geologic interpretations in slowly cooled continental interiors. 


\section{Author Contributions}

CRediT author statement. K. McDannell: Conceptualization, Investigation, Methodology, Formal analysis, Visualization, Funding acquisition, Writing - original draft; P. O'Sullivan: Formal analysis, Methodology, Resources; K. Gallagher: Conceptualization, Validation, Writing - Review \& Editing; S. Boroughs: Formal analysis, Methodology, Resources

\section{Acknowledgments}

The Government of Canada Geomapping for Energy and Minerals Program (GEM-2) supported K.T.M. at the Geological Survey of Canada, Calgary from 2017-2020 during data collection. This work was specifically supported with funds to K.T.M. through the GEM-2 geological synthesis. Thanks to Michel Plouffe (GSC Ottawa) for GEM project coordination. Nicolas Pinet (GSC Québec) and the Manitoba Geological Survey are thanked for providing rocks for analyses.

\section{Data Availability}

Fission track data, electron microprobe data, and QTQt models are available from the Open Science Framework (OSF) repository: https://osf.io/73u8j/ 


\section{References}

Barbarand, J., Carter, A., Wood, I., Hurford, T., 2003. Compositional and structural control of fission-track annealing in apatite. Chemical Geology 198, 107-137. doi:10.1016/S0009-2541(02)00424-2.

Burgess, P.M., 2019. Phanerozoic Evolution of the Sedimentary Cover of the North American Craton, in: The Sedimentary Basins of the United States and Canada. Elsevier. volume 5, pp. 39-75. doi:10.1016/ B978-0-444-63895-3.00002-4.

Burrus, J., Osadetz, K., Wolf, S., Doligez, B., Visser, K., Dearborn, D., 1996. A two-dimensional regional basin model of williston basin hydrocarbon systems. AAPG Bulletin 80, 265-291. doi:10.1306/ 64ed87aa-1724-11d7-8645000102c1865d.

Carlson, W.D., Donelick, R.A., Ketcham, R.A., 1999. Variability of apatite fission-track annealing kinetics: I. Experimental results. American Mineralogist 84, 1213-1223. doi:10.2138/am-1999-0901.

Chew, D.M., Donelick, R.A., 2012. Combined apatite fission track and U-Pb dating by LA-ICP-MS and its application in apatite provenance analysis. Quantitative mineralogy and microanalysis of sediments and sedimentary rocks: Mineralogical Association of Canada Short Course 42, 219-247. URL: http: //hdl.handle.net/2262/67003.

Cogné, N., Chew, D.M., Donelick, R.A., Ansberque, C., 2020. LA-ICP-MS apatite fission track dating: A practical zeta-based approach. Chemical Geology 531, 119302. doi:10.1016/j.chemgeo.2019.119302.

Crowley, K.D., 1985. Thermal significance of fission-track length distributions. Nuclear Tracks and Radiation Measurements (1982) 10, 311-322. doi:10.1016/0735-245X(85)90120-6.

Donelick, R.A., Ketcham, R.A., Carlson, W.D., 1999. Variability of apatite fission-track annealing kinetics: II. Crystallographic orientation effects. American Mineralogist 84, 1224-1234. doi:10.2138/am-1999-0902.

Donelick, R.A., O'Sullivan, P.B., Ketcham, R.A., 2005. Apatite Fission-Track Analysis. Reviews in Mineralogy and Geochemistry 58, 49-94. doi:10.2138/rmg.2005.58.3.

Duddy, I.R., Green, P.F., Laslett, G.M., 1988. Thermal annealing of fission tracks in apatite 3. Variable temperature behaviour. Chemical Geology: Isotope Geoscience Section 73, 25-38. doi:10.1016/0168-9622 (88) 90019-X.

Fleischer, R.L., Price, P.B., 1963. Tracks of charged particles in high polymers. Science 140, 1221-1222. doi:10.1126/science.140.3572.1221. 
Gallagher, K., 2012. Transdimensional inverse thermal history modeling for quantitative thermochronology. Journal of Geophysical Research: Solid Earth 117. URL: http://doi .wiley.com/10.1029/2011JB008825, doi:10.1029/2011JB008825.

Galloway, J.M., Armstrong, D., Lavoie, D., 2012. Palynology of the INCO Winisk \#49204 core (54²18’30"N, $87^{\circ} 02^{\prime} 30^{\prime \prime W}$, NTS 43L/6), Ontario. URL: https://geoscan.nrcan.gc.ca/starweb/geoscan/servlet . starweb?path=geoscan/fulle . web\&search1=R=290985, doi:10 . 4095/290985.

Gleadow, A.J., Duddy, I.R., 1981. A natural long-term track annealing experiment for apatite. Nuclear Tracks 5, 169-174. doi:10.1016/0191-278X (81)90039-1.

Gleadow, A.J., Duddy, I.R., Green, P.F., Lovering, J.F., 1986. Confined fission track lengths in apatite: a diagnostic tool for thermal history analysis. Contributions to Mineralogy and Petrology 94, 405-415. doi:10.1007/BF00376334.

Green, P.F., Duddy, I.R., Gleadow, A.J., Tingate, P.R., Laslett, G.M., 1985. Fission-track annealing in apatite: Track length measurements and the form of the Arrhenius plot. Nuclear Tracks and Radiation Measurements (1982) 10, 323-328. doi:10.1016/0735-245X (85)90121-8.

Green, P.F., Duddy, I.R., Gleadow, A.J., Tingate, P.R., Laslett, G.M., 1986. Thermal annealing of fission tracks in apatite. 1. A qualitative description. Chemical Geology: Isotope Geoscience Section 59, 237-253. doi:10.1016/0168-9622(86)90074-6.

Green, P.F., Duddy, I.R., Laslett, G.M., Hegarty, K.A., Gleadow, A.J., Lovering, J.F., 1989. Thermal annealing of fission tracks in apatite 4. Quantitative modelling techniques and extension to geological timescales. Chemical Geology: Isotope Geoscience Section 79, 155-182. doi:10.1016/0168-9622(89)90018-3.

Hendriks, B.W., Redfield, T.F., 2006. Reply to: Comment on "Apatite Fission Track and (U-Th)/He data from Fennoscandia: An example of underestimation of fission track annealing in apatite" by B. W. H. Hendriks and T. F. Redfield. Earth and Planetary Science Letters 248, 569-577. doi:10.1016/j.eps1.2006.06.022.

Hoffman, P.F., 1989. Precambrian geology and tectonic history of North America, in: Bally, A.W., Palmer, A.R. (Eds.), The geology of North America - an overview. The Geological Society of America. volume A. chapter 16, pp. 447-512. doi:https://doi.org/10.1130/DNAG-GNA-A . 447.

Issler, D.R., McDannell, K.T., O’Sullivan, P.B., Lane, L.S., 2021. Simulating sedimentary burial cycles - Part 2: Elemental-based multikinetic apatite fission-track interpretation and modelling techniques illustrated using examples from northern Yukon. Geochronology Discussions, 1-37doi:10.5194/gchron-2021-22. 
Ketcham, R.A., 2015. Technical Note: Calculation of stoichiometry from EMP data for apatite and other phases with mixing on monovalent anion sites. American Mineralogist 100, 1620-1623. doi:10.2138/am-2015-5171.

Ketcham, R.A., 2019. Fission-Track Annealing: From Geologic Observations to Thermal History Modeling, in: Fission-Track Thermochronology and its Application to Geology. Springer, pp. 49-75. doi:10.1007/ $978-3-319-89421-8\left\{\backslash_{-}\right\} 3$.

Ketcham, R.A., van der Beek, P., Barbarand, J., Bernet, M., Gautheron, C., 2018. Reproducibility of Thermal History Reconstruction From Apatite Fission-Track and (U-Th)/He Data. Geochemistry, Geophysics, Geosystems 19, 2411-2436. doi:10.1029/2018GC007555.

Ketcham, R.A., Donelick, R.A., Carlson, W.D., 1999. Variability of apatite fission-track annealing kinetics: III. Extrapolation to geological time scales. American Mineralogist 84, 1235-1255. doi:10.2138/am-1999-0903.

Kohn, B., Gleadow, A., 2019. Application of Low-Temperature Thermochronology to Craton Evolution, in: Malusá, M.G., Fitzgerald, P.G. (Eds.), Fission-Track Thermochronology and its Application to Geology. Springer, Cham.. chapter 21, pp. 373-393.

Laslett, G.M., Green, P.F., Duddy, I.R., Gleadow, A.J., 1987. Thermal annealing of fission tracks in apatite 2. A quantitative analysis. Chemical Geology: Isotope Geoscience Section 65, 1-13. doi:10.1016/ 0168-9622(87) 90057-1.

Laslett, G.M., Kendall, W.S., Gleadow, A.J., Duddy, I.R., 1982. Bias in measurement of fission-track length distributions. Nuclear Tracks and Radiation Measurements (1982) 6, 79-85. doi:10.1016/0735-245X(82) $90031-\mathrm{X}$.

Lavoie, D., Pinet, N., Zhang, S., Reyes, J., Jiang, C., Ardakani, O.H., Savard, M.M., Dhillon, R.S., Chen, Z., Dietrich, J.R., 2019. Hudson Bay, Hudson Strait, Moose River, and Foxe basins: synthesis of the research activities under the Geomapping for Energy and Minerals (GEM) programs 2008-2018. doi:https://doi.org/10.4095/314653.

Li, W., Cheng, Y., Feng, L., Niu, J., Liu, Y., Skuratov, V.A., Zdorovets, M.V., Boatner, L.A., Ewing, R.C., 2021. Alpha-decay induced shortening of fission tracks simulated by in situ ion irradiation. Geochimica et Cosmochimica Acta 299,1-14. doi:10.1016/j.gca.2021.01.022.

McDannell, K.T., 2020. Notes on statistical age dispersion in fission-track datasets: the chi-square test, annealing variability, and analytical considerations. EarthArXiv , 1-4doi:10.31223/OSF. IO/UJ4HX. 
McDannell, K.T., 2022. Models for: A heuristic approach for modeling the surface histories of cratons using apatite fission-track "super samples". OSF URL: https://osf.io/73u8j/, doi:10.17605/0SF. I0/73U8J.

McDannell, K.T., Flowers, R.M., 2020. Vestiges of the ancient: Deep-time noble gas thermochronology. Elements 16, 325-330. doi:10.2138/gselements.16.5.325.

McDannell, K.T., Issler, D.R., 2021. Simulating sedimentary burial cycles - Part 1: Investigating the role of apatite fission track annealing kinetics using synthetic data. Geochronology 3, 321-335. doi:10.5194/ gchron-3-321-2021.

McDannell, K.T., Issler, D.R., O'Sullivan, P.B., 2019a. Radiation-enhanced fission track annealing revisited and consequences for apatite thermochronometry. Geochimica et Cosmochimica Acta 252, 213-239. doi:10.1016/j.gca.2019.03.006.

McDannell, K.T., Pinet, N., Issler, D.R., 2021. Exhuming the Canadian Shield: preliminary interpretations from low-temperature thermochronology and significance for the sedimentary succession of the Hudson Bay Basin. EarthArXiv doi:10.31223/X54P5F.

McDannell, K.T., Schneider, D.A., Zeitler, P.K., O’Sullivan, P.B., Issler, D.R., 2019b. Reconstructing deep-time histories from integrated thermochronology: An example from southern Baffin Island, Canada. Terra Nova 31, 189-204. doi:10.1111/ter.12386.

Norris, A., 1993. Hudson Platform - Geology, in: Stott, D., Aitken, J. (Eds.), Sedimentary Cover of the Craton in Canada. The Geological Society of America, pp. 653-700. doi:10.1130/dnag-gna-d1.653.

Norris, G., 1977. Palynofloral evidence for terrestrial Middle Jurassic in the Moose River Basin, Ontario. Canadian Journal of Earth Sciences 14, 153-158. doi:10.1139/e77-018.

Pinet, N., Lavoie, D., Dietrich, J., Hu, K., Keating, P., 2013. Architecture and subsidence history of the intracratonic Hudson Bay Basin, northern Canada. Earth-Science Reviews 125, 1-23. doi:10.1016/j. earscirev.2013.05.010.

Rahn, M., Seward, D., 2000. How many track lengths do we need? On Track (unpublished newsletter) 10, 14-17. URL: https://repositories.lib.utexas.edu/handle/2152/30056.

Rainbird, R.H., Stern, R.A., Rayner, N., Jefferson, C.W., 2007. Age, provenance, and regional correlation of the Athabasca Group, Saskatchewan and Alberta, constrained by igneous and detrital zircon geochronology. Technical Report. Geological Survey of Canada. doi:10.4095/223761. 
Sage, R.P., 2000. Kimberlites of the Attawapiskat area, James Bay Lowlands, northern Ontario. Technical Report 341. Ontario Geological Survey, Open File Report 6019. URL: http://www.geologyontario.mndm. gov. on .ca/mndmaccess/mndm_dir . asp?type=pub\&id=0FR6019.

Sloss, L.L., 1963. Sequences in the cratonic interior of north America. Bulletin of the Geological Society of America 74, 93-114. doi:10.1130/0016-7606(1963)74[93:SITCI0] 2.0.C0;2.

Telford, P.G., Long, D.G., 1986. Mesozoic Geology of the Hudson Platform, in: Elsevier Oceanography Series. Elsevier. volume 44. chapter 3, pp. 43-54. doi:10.1016/S0422-9894(08)70896-1.

Tillement, B.A., Peniguel, G., Guillemin, J.P., 1976. Marine Pennsylvanian Rocks in Hudson Bay. Bulletin of Canadian Petroleum Geology 24, 418-439. doi:10.35767/gscpgbull.24.3.418.

Tripati, A., Darby, D., 2018. Evidence for ephemeral middle Eocene to early Oligocene Greenland glacial ice and pan-Arctic sea ice. Nature Communications 9, 1038. doi:10.1038/s41467-018-03180-5.

Vermeesch, P., 2018. IsoplotR: A free and open toolbox for geochronology. Geoscience Frontiers 9, $1479-1493$. doi:10.1016/j.gsf .2018.04.001.

Vermeesch, P., 2019. Statistics for Fission-Track Thermochronology, in: Malusa, M.G., Fitzgerald, P. (Eds.), Fission-Track Thermochronology and its Application to Geology. 1 ed.. Springer International Publishing, New York. chapter 6, pp. 109-122. doi:10.1007/978-3-319-89421-8\{\_\}6.

Wheeler, J.O., Hoffman, P., Card, K., Davidson, A., Sanford, B.V., Okulitch, A., W.R., R., 1997. Geological map of Canada version 1.0. URL: https ://doi.org/10.4095/208175, doi:10.4095/208175. 